Printed in the Unıted States of America Avallable from National Technical Information Service

US Department of Commerce

5285 Port Royal Road, Sprıngfield, Vırgınıa 22161

NTIS price codes-Printed Copy A04, Microfiche A01

This report was prepared as an account of work sponsored by an agency of the United States Government Neither the United States Government nor any agency thereof, nor any of their employees, makes any warranty express or implied, or assumes any legal liability or responsibility for the accuracy, completeness, or usefulness of any information, apparatus, product, or process disclosed, or represents that its use would not infringe privately owned rights Reference here in to any specific commercial product, process, or service by trade name, trademark, manufacturer or otherwise, does not necessarily constitute or imply its endorsement recommendation, or favoring by the United States Government or any agency thereof The views and opınions of authors expressed herein do not necessarily state or reflect those of the United States Government or any agency thereof 


\section{DISCLAIMER}

This report was prepared as an account of work sponsored by an agency of the United States Government. Neither the United States Government nor any agency Thereof, nor any of their employees, makes any warranty, express or implied, or assumes any legal liability or responsibility for the accuracy, completeness, or usefulness of any information, apparatus, product, or process disclosed, or represents that its use would not infringe privately owned rights. Reference herein to any specific commercial product, process, or service by trade name, trademark, manufacturer, or otherwise does not necessarily constitute or imply its endorsement, recommendation, or favoring by the United States Government or any agency thereof. The views and opinions of authors expressed herein do not necessarily state or reflect those of the United States Government or any agency thereof. 


\section{DISCLAIMER}

Portions of this document may be illegible in electronic image products. Images are produced from the best available original document. 
ORNL/TM-7848

Dist. Category UC-86

Contract No. W-7405-eng-26

Consolidated Fuel Reprocessing Program

\title{
EXPERIMENTAL DEMONSTRATION OF MICROSCOPIC PROCESS MONITORING
}

\author{
R. D. Hurt \\ S. J. Hurrell \\ A. B. Crawford \\ Engineering Technology Division \\ J. W. Wachter \\ Fuel Recycle Division \\ T. L. Hebble \\ Computer Sciences Division
}

Date Published: January 1982

NOTICE This document contains information of a prelımınary nature. It is subject to revision or correction and therefore does not represent a final report.

OAK RIDGE NATIONAL LABORATORY

Oak Ridge, Tennessee 37830 operated by UNION CARBIDE CORPORATION for DEPARTMENT OF ENERGY 


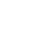

. 


\section{CONTENTS}

ABSTRACT $\ldots \ldots \ldots \ldots \ldots \ldots \ldots \ldots \ldots \ldots \ldots \ldots \ldots \ldots \ldots \ldots \ldots$

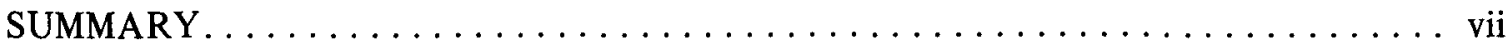

1. OBJECTIVES OF PROCESS MONITORING $\ldots \ldots \ldots \ldots \ldots \ldots \ldots \ldots \ldots \ldots \ldots 1$

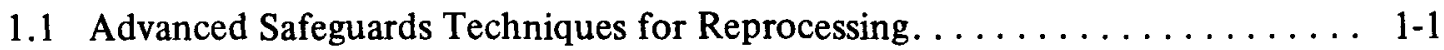

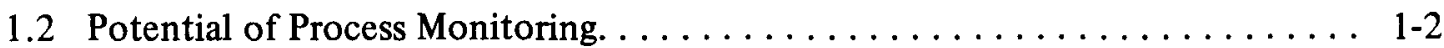

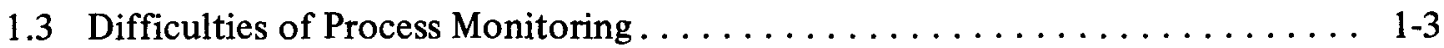

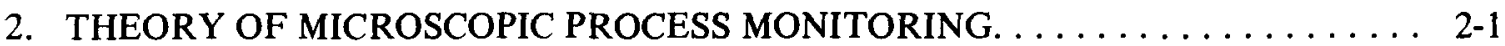

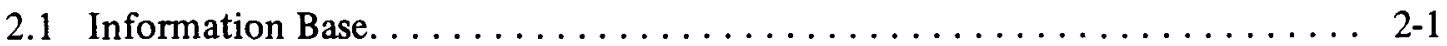

2.2 Process Variable Predictions . . . . . . . . . . . . . . . . . . . . . $2-1$

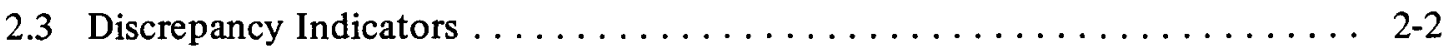

2.4 MPM Messages. . . . . . . . . . . . . . . . . . . . . . . 2-2

3. MPM EXPERIMENTS AT THE BARNWELL NUCLEAR FUEL PLANT . . . . . . 3-1

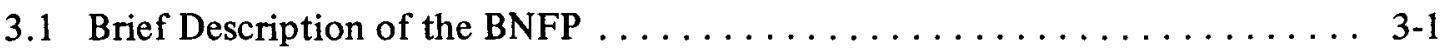

3.1 .1 Process layout and operation. ................... 3-1

3.1.2 Process measurement instruments................ 3-2

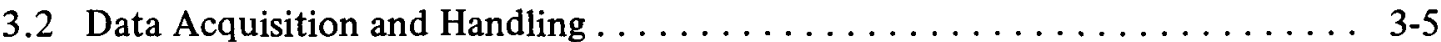

3.3 Prediction Equations. . . . . . . . . . . . . . . . . . . . . . . 3-8

3.4 Prediction Uncertainties . . . . . . . . . . . . . . . . . . . . . . . 3-10

3.5 Discrepancy Patterns........................ 3-11

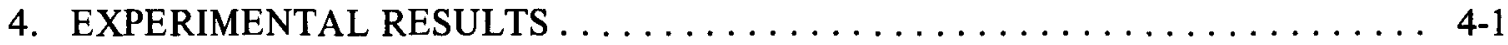

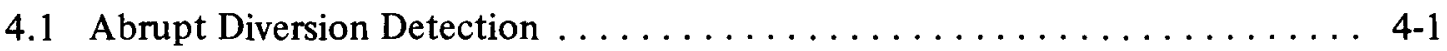

4.1.1 Minirun three diversion tests................... 4-1

4.1 .2 Minirun four diversion tests. . . . . . . . . . . . . . . . . 4-3

4.1 .3 False alarms. . . . . . . . . . . . . . . . . . . . . . 4-7

4.2 Batch Transfers. . . . . . . . . . . . . . . . . . . . . . . . 4-8

4.3 Probe Blowouts. . . . . . . . . . . . . . . . . . . . . . 4-9

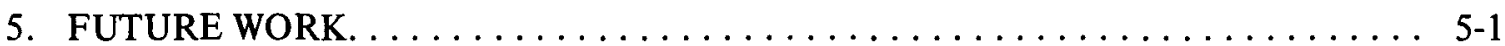

5.1 Miscellaneous Measurement Anomalies. . . . . . . . . . . . . . 5-1

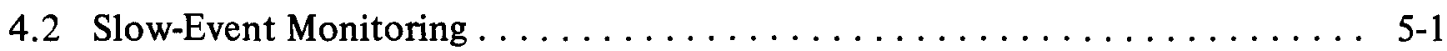

6. CONCLUSIONS .............................. $6-1$

7. REFERENCES ............................. $7-1$ 



\begin{abstract}
Microscopic process monitoring (MPM) is a material control strategy designed to use standard process control data to provide expanded safeguards protection of nuclear fuel cycle facilities. The MPM methodology identifies process events by recognizing significant patterns of changes in on-line measurements. The goals of MPM are to detect diversions of nuclear material and to provide information on process status useful to other facility safeguards operations.
\end{abstract}





\section{SUMMARY}

Measurement technologies for process control and other operational applications have improved considerably in the last several years, especially in the degree to which data from process instrumentation is accessible by computer. The potential safeguards applications of this type of process instrument data have been widely recognized. A safeguards strategy, based primarily on the data from process control instrumentation called microscopic process monitoring (MPM), has been developed for reprocessing plant applications at the Oak Ridge National Laboratory.

A broadly based microscopic process monitoring system would provide maximum flexibility in detecting diversions by helping to identify anomalous process conditions and events that would indicate a diversion. A large quantity and variety of measurement information would also maximize the tamper-indicating capabilities of the system if suitable relationships between the measured parameters could be found. The MPM procedure provides a means for direct inclusion of all types of process data in the decision-making process. To make use of such data, a process monitoring methodology must exploit correlations between various measured parameters and the status of the nuclear material in the process. As the name "microscopic" implies, the MPM methodology is based on local correlations between a small number of process variables over a short period of time, thus avoiding the complexity of modeling wide-range or long-term correlations. Microscopic process monitoring is not a material accounting strategy and does not depend on material balance concepts over large areas of the plant.

The first step of the MPM technique is to predict a future value for each measured variable. Linear extrapolations and volume conservation equations are used for most MPM predictions. Even with frequent updating, the individual models used in MPM are not usually versatile enough to accurately predict future values. Fortunately, it is possible to assemble a set of simple models such that some of them will generate reasonable predictions at any particular time.

Each process variable measurement is then compared with one or more corresponding predictions. Specifically, the measured value is subtracted from the predicted value, and the difference is divided by an uncertainty factor. The uncertainty factor reflects the combined effect of the uncertainty of the measurement and the uncertainty of the prediction.

For each comparison between measurement and prediction, a unitless discrepancy statistic, denoted $Z$, is calculated with the following formula:

$$
Z=\frac{X-Y}{\left(\mathrm{~s} x^{2}+\mathrm{sy}^{2}\right)^{1 / 2}},
$$

where

$$
\begin{aligned}
& X=\text { the predicted value of a variable, } \\
& Y=\text { the measured value of a variable, } \\
& \mathrm{s}_{x}=\text { the uncertainty of the prediction, } \\
& \mathrm{s}_{y}=\text { the uncertainty of the measurement. }
\end{aligned}
$$


This statistic is a fair measure of the significance of the difference between observation and expectation.

The MPM methodology bases safeguards decisions not on the values of the individual $z$ statistics, but on the value of an event statistic called $r$. When a particular event occurs, that is, a diversion or a batch transfer, it tends to generate a distinct pattern of nonzero $z$ statistics which are combined into a unique value of $r$ corresponding to that event. Hence, the MPM methodology permits identification of normal process events; other events are interpreted as possible diversions.

During FY 1980 and FY 1981, the MPM concept was tested at the Barnwell Nuclear Fuel Plant (BNFP) in Barnwell, South Carolina. The plant has not yet been licensed to process spent nuclear fuel; however, cold operation with natural uranium is permissible. For the MPM experiments, the plutonium extraction and purification cycles of the BNFP were operated with natural uranium feed solution for six 7-day periods, and data from 52 on-line process measurements were analyzed and recorded. Controlled diversion experiments were conducted during the periods to test the abrupt diversion detection sensitivity of MPM. Volumes of $1,2,5,10$, and $20 \mathrm{~L}$ were removed from some of the tanks used in the demonstration. In all cases, the solution was removed from the tanks as rapidly as possible.

The BNFP experiments clearly demonstrated that MPM can be implemented in a large reprocessing plant on a standard minicomputer system. No fundamental problems were encountered in accomplishing the rapid and frequent data acquisition required for MPM. The experiments concentrated on the detection and identification of abrupt process phenomena, that is, those that cause a measurable change in process parameters within $8 \mathrm{~min}$. No attempt was made to address protracted diversions. Data were compiled on the sensitivities and false alarm rates associated with these types of identification. In general, the detection sensitivity was found to be dependent on the mode of operation of the tank (i.e., static or constantly filling or emptying) and the accuracy of the instrumentation. The MPM technique proved success ful in identifying abrupt diversion and batch transfers.

The feasibility of applying the MPM concept in an operating plant has been demonstrated. Future demonstrations will use binary valve and pump sensors to assist in the identification of batch transfers. Further work on slow-event monitoring (protracted diversions, instrument drift, and pulse column events) using MPM is planned. After an optimum MPM software package has been developed, current plans call for integration of the MPM with dynamic accounting and physical protection to form a comprehensive safeguards system. 


\section{OBJECTIVES OF PROCESS MONITORING}

\subsection{Advanced Safeguards Techniques for Reprocessing}

The use of nuclear power carries with it a risk that uranium or plutonium may be diverted from the civilian fuel cycle into unauthorized or undesirable activities. A widely expressed concern is that terrorists or criminals might acquire such nuclear materials by defeating the safeguards systems implemented by nuclear facility operators. ${ }^{1-3}$ More serious is the potential danger that nations not currently possessing nuclear weapons might use civilian nuclear facilities to acquire raw weapons material with relative ease. ${ }^{4-6}$ It should be emphasized that proven cases of subnational diversion have been few and that none of the nations with demonstrated nuclear weapons capabilities have used commercial nuclear facilities to acquire weapons ingredients. ${ }^{4,7-9}$ Nevertheless, as more nuclear fuel cycle facilities are deployed around the world, the risk of such diversion may increase.

Spent fuel reprocessing plants are especially vulnerable to nuclear material diversion. ${ }^{5}$ These facilities ty pically handle large quantities of nuclear material, much of which is relatively uncontaminated in the final stages of the process. Furthermore, much of the nuclear material in a reprocessing plant is in the form of liquids or powders and is thus more accessible to theft than the material in, for example, a nuclear reactor facility. ${ }^{10,11}$ Only a few reprocessing facilities are currently operating around the world; most of these are small and operate in connection with military programs. ${ }^{11}$ To the extent that breeder reactors are deployed in the future, however, reprocessing plants will become more numerous and probably larger. An extensive commitment to the recycle of plutonium in conventional reactors would have a similar effect. ${ }^{5}$

Reprocessing plants and other fuel cycle facilities have traditionally been safeguarded by a combination of physical security measures to prevent unauthorized access to nuclear material, long-term material balances to account for all nuclear material, and procedural controls over the use and movement of nuclear material. To protect against subnational diversion, these systems are generally implemented by the facility operating staff in accordance with national regulatory guidelines and are usually accompanied by an armed response capability. ${ }^{12}$ For plants subject to international safeguards, additional requirements may be imposed to facilitate inspection by international authorities. Currently, no international body has punitive authority; the goal of international safeguards is to detect national diversion and alert the international community. ${ }^{6,8,13}$

Despite the successful safeguards record compiled by the nuclear industry, there is general agreement within the safeguards community that conventional techniques may not be adequate to safeguard future fuel cycle facilities with the effectiveness and reliability generally desired..$^{2,8,14,15}$ Conventional material balances, based on physical inventories of nuclear material, cannot be closed frequently and accurately enough to meet the anticipated safeguards needs of the next generation of plants. ${ }^{16}$ Traditional material controls are likewise considered too inflexible and too insensitive to provide credible protection of future facilities. ${ }^{2}$ Less concern exists about the availability of adequate physical security techniques, but these techniques alone are insufficient and do not contribute substantially to international safeguards. Accordingly, several advanced safeguards concepts and many supporting technologies are being developed with the support of the U.S. Department of Energy (DOE), 
the U.S. Nuclear Regulatory Commission (NRC), the International Atomic Energy Agency (IAEA), and the national governments of several countries. Although it is beyond the scope of this report to discuss each advanced concept, noting some of their common features may help place the development of microscopic process monitoring in perspective.

Most advanced safeguards concepts offer an improvement over conventional techniques because they take advantage of additional information. Frequently, such information is assumed to come from special safeguards sensors installed for this purpose. Penetration monitoring, a concept that has received much attention, ${ }^{17,18}$ relies on a network of mostly binary sensors deployed on specified penetrations passing through a predefined containment boundary. Penetration monitoring aims to ensure that all nuclear material remains within this enclosed region. Another promising advanced concept is dynamic accounting. ${ }^{16,19}$ This technique attempts to detect diversions and accounts for the location of in-process nuclear material by performing frequent material balances around portions of a chemical process. Dynamic accounting generally requires more accurate, in-line measurements of nuclear material flows and inventories than are required for process control. Various permutations of penetration monitoring and dynamic accounting have been conceptually developed in considerable detail and have been demonstrated with modest success. ${ }^{16,19,20,21}$

Independent of safeguards considerations, measurement technologies for process control and other operational applications have improved considerably in the last several years, especially in the degree to which data from process instrumentation is accessible by computer. ${ }^{10,22}$ The potential safeguards applications of this type of instrumentation have been widely recognized. ${ }^{2,23,24}$ For the purposes of this report, a safeguards strategy based primarily on the data from process control instrumentation will be called process monitoring. The remainder of this report will deal with the advantages and disadvantages of process monitoring strategy.

\subsection{Potential of Process Monitoring}

Process monitoring can potentially provide a considerable diversion detection capability without requiring the development or installation of specialized safeguards instrumentation. This is a substantial asset. In the interest of economical plant operation, minimizing the cost and complexity of safeguards requirements is desirable, and specialized instrumentation is frequently one of the major cost factors. Furthermore, specialized instrumentation is often more complex and more difficult to maintain than standard process control instrumentation and thus has a tendency to intrude on process operations. ${ }^{10}$ Economic advantages could accrue to the extent that process monitoring can minimize the need for other safeguards systems.

For some facilities or portions of facilities, process monitoring alone would not be expected to provide sufficient diversion detection capability. Even in such cases, however, process monitoring can supplement other safeguards subsystems with valuable auxiliary information. Dynamic accounting and penetration monitoring will only be effective if their networks of sensors and measurement instruments are operating reliably and are not tampered with. Process monitoring can provide the back-up data needed to diagnose problems and have confidence in the results provided by the other subsystems.

In practice, an effective safeguards system should integrate the best features of process monitoring, penetration monitoring, dynamic accounting, and other subsystem concepts. 
Because few diversions from civilian nuclear facilities have been documented, little historical basis exists for judging what a diversion might look like.4,8,9 Thus, building diversion detection systems on a large and diverse information base would be prudent. Considering the flexible capabilities of a national diverter, this general policy would be especially appropriate for international safeguards. Process monitoring, by making use of all available process control data, would be a vital element of a broadly based diversion detection system.

\subsection{Difficulties of Process Monitoring}

Despite its prospective advantages, process monitoring is encumbered with certain technical difficulties, some of which differ from those connected with other advanced safeguards concepts. The abundance and diversity of data employed by process monitoring present data interpretation problems. Many process data are only indirectly related to safeguards concerns, either because they come from parts of the process that do not contain nuclear material or because they bear only a slight relationship to nuclear material content. How to make use of indirect information and whether to do so are difficult questions. To complicate matters further, most process control measurements are relatively inaccurate compared with the specialized measurements used in most safeguards systems.

It is important that a safeguards system provide a clear, concise indication of the status of a facility's nuclear material. In international safeguards applications, where the onsite inspector may not be intimately familar with the technical details of a particular facility, this goal is especially vital. Translating a large quantity of diverse, inaccurate process data in to an unambiguous safeguards signal is the foremost challenge of process monitoring.

A process monitoring strategy called microscopic process monitoring (MPM) is being developed by Oak Ridge National Laboratory (ORNL). The theory of MPM and its experimental demonstration at the BNFP are discussed in the remaining chapters of this report. 


\section{THEORY OF MICROSCOPIC PROCESS MONITORING}

\subsection{Information Base}

One of the basic premises of MPM is that useful safeguards information can be obtained from a variety of available process data. As discussed in the preceding section, a broadly based process monitoring system would provide maximum flexibility in detecting diversions. A large quantity and variety of measurement information would also maximize the tamperindicating capabilities of the system if suitable relationships between the measured parameters could be found. The MPM procedure provides a means for direct inclusion of all types of process data in the decision-making process.

The initial development of MPM was based on the assumption that all input data would come from standard process control or other operations-related instrumentation without reliance on specially installed safeguards instruments. Of course, incorporating data from special safeguards sensors into the MPM methodology would be possible. However, one of the advantages of MPM is that it does not require data from such sensors to provide valuable safeguards information. Accordingly, the use of data from standard process instrumentation has been emphasized in the theoretical development of MPM and in its experimental demonstration.

The current MPM methodology has been designed to use data from on-line instrumentation. No methodological reason would prohibit the use of laboratory measurement data or other off-line information. However, rapid diversion detection and on-line process diagnostics have always been envisioned as the most valuable safeguards applications of MPM. For this reason, existing MPM programs have been designed to use only data from on-line instruments.

\subsection{Process Variable Predictions}

Unlike most other advanced safeguards concepts, process monitoring is not afflicted by a shortage of data. Future reprocessing facilities will apparently be well equipped with on-line process instruments and the computer capabilities to access and manipulate the resulting data. ${ }^{25}$ The difficulty lies in extracting safeguards information contained in the process data. The values of most process parameters change frequently during normal process operation, and it is not always easy to distinguish between normal changes and a potential diversion or other safeguards incident.

The first step of the MPM technique is to predict a future value for each measured variable. Because the number of variables involved is large, the use of simple prediction models is desirable. Complex models tend to demand too much computing capacity and are difficult to construct and interpret. As described in Sect. 3, linear extrapolations and volume conservation equations are used for most MPM predictions. As one might expect, such simple models are often in error; even with frequent updating, the individual models used in MPM are not versatile enough to be accurate most of the time. Fortunately, it is possible to assemble a set of simple models such that some of them will generate reasonable predictions at any particular time. 


\subsection{Discrepancy Indicators}

In the MPM methodology, each process variable measurement is compared with one or more corresponding predictions. Specifically, the measured value is subtracted from the predicted value, and the difference is divided by an uncertainty factor. The uncertainty factor reflects the combined effect of the uncertainty of the measurement and the uncertainty of the prediction.

For each comparison between measurement and prediction, a unitless discrepancy statistic, denoted $z^{\prime}$, is calculated with the following formula:

$$
z^{\prime}=\frac{x-y}{\left(s x^{2}+s y^{2}\right)^{1 / 2}},
$$

where

$$
\begin{aligned}
& x=\text { the predicted value of a variable, } \\
& y=\text { the measured value of a variable, } \\
& s_{x}=\text { the uncertainty of the prediction, } \\
& s_{y}=\text { the uncertainty of the measurement. }
\end{aligned}
$$

In many situations, this statistic is a fair measure of the significance of the difference between observation and expectation.

The uncertainty of a measurement is due to the various types of error that affect all process instruments. For most purposes, the MPM methodology functions by detecting changes in parametervalues;generally, it is not vital to know the actual value of a parameter. Hence, the imprecision of a measurement technique can usually be used as the measurement uncertainty.

The uncertainty of a prediction is more complicated. It must reflect the inaccuracies of the measurements used to generate the prediction as well as the uncertainty of the prediction model itself. Determining an appropriate value for this quantity on a strictly theoretical basis is difficult. In practice, its value is adjusted to tune the response of the MPM analysis. This feature of the MPM methodology will be discussed in more detail in later sections.

\subsection{MPM Messages}

The occurrence of a nonzero $z$ statistic means that the observed value of a parameter is different from its expected value. In and of itself, this information is not of much interest to a safeguards authority. A nonzero $z$ statistic could be caused by a diversion; but it is also true that a specific nonzero $z$ could be caused by an erroneous measurement or a faulty prediction. Bear in mind that MPM is designed to use standard process control instruments and that such instruments generally have precisions of 5\% or worse and are subject to many types of failure or malfunction. In addition, the prediction models used for MPM may not correctly describe certain aspects of the process. Given the simplicity of the MPM models in general, any particular model will probably not be able to make accurate predictions all of the time. 
For these reasons, the MPM methodology bases safeguards decisions not on the values of the individual $z$ statistics, but on the value of a statistic, called $r$, that combines several $z$ values. When a particular process event occurs - a diversion, a batch transfer, an instrument malfunction, or some other phenomenon - it tends to generate a distinct pattern of nonzero $z$ statistics. The MPM methodology identifies process events by recognizing these patterns.

To recognize patterns of nonzero $z$ 's, MPM begins by organizing all of the $z$ 's from throughout the process into a discrepancy vector $Z$. ( $Z$ will be used to indicate a discrepancy vector, and $z$ will be used to refer to one of the vector's elements.) Each element of this vector, which is updated whenever new data are available, represents the most recent discrepancy between a process variable measurement and its predicted value.

The discrepancy vector is premultiplied by a pattern matrix $\mathbf{P}$ that serves to combine selected elements of $\mathbf{Z}$ into elements of a new vector, $\mathbf{R}$. The $i$ th $(i=1,2, \ldots n)$ element of $\mathbf{R}$ is determined by

$$
r_{i}=p_{i 1} z_{1}+p_{i 2} z_{2}+\cdots+p_{i n} z_{n}
$$

Figure 1 illustrates this methodology in simplified form.

When any particular event occurs, a predictable subset of $z^{\prime}$ values is expected to be significantly nonzero. Furthermore, it is usually possible to predict whether the affected

ORNL DWG 81-1366R

PATTERN MATRIX

$\left[\begin{array}{ccc}p_{11} & p_{12} \ldots \ldots & p_{1 n} \\ p_{21} & p_{22} \ldots \cdots & p_{2 n} \\ \vdots & \vdots & \vdots \\ \vdots & \vdots & \vdots \\ \vdots & \vdots & \vdots \\ \vdots & \vdots & \vdots \\ p_{m 1} & p_{m 2} & p_{m n}\end{array}\right]$
DISCREPANCY

VECTOR

$\times\left[\begin{array}{c}z_{1} \\ z_{2} \\ \vdots \\ \vdots \\ \vdots \\ \vdots \\ \vdots \\ \vdots \\ z_{n}\end{array}\right]$
EVENT

VECTOR

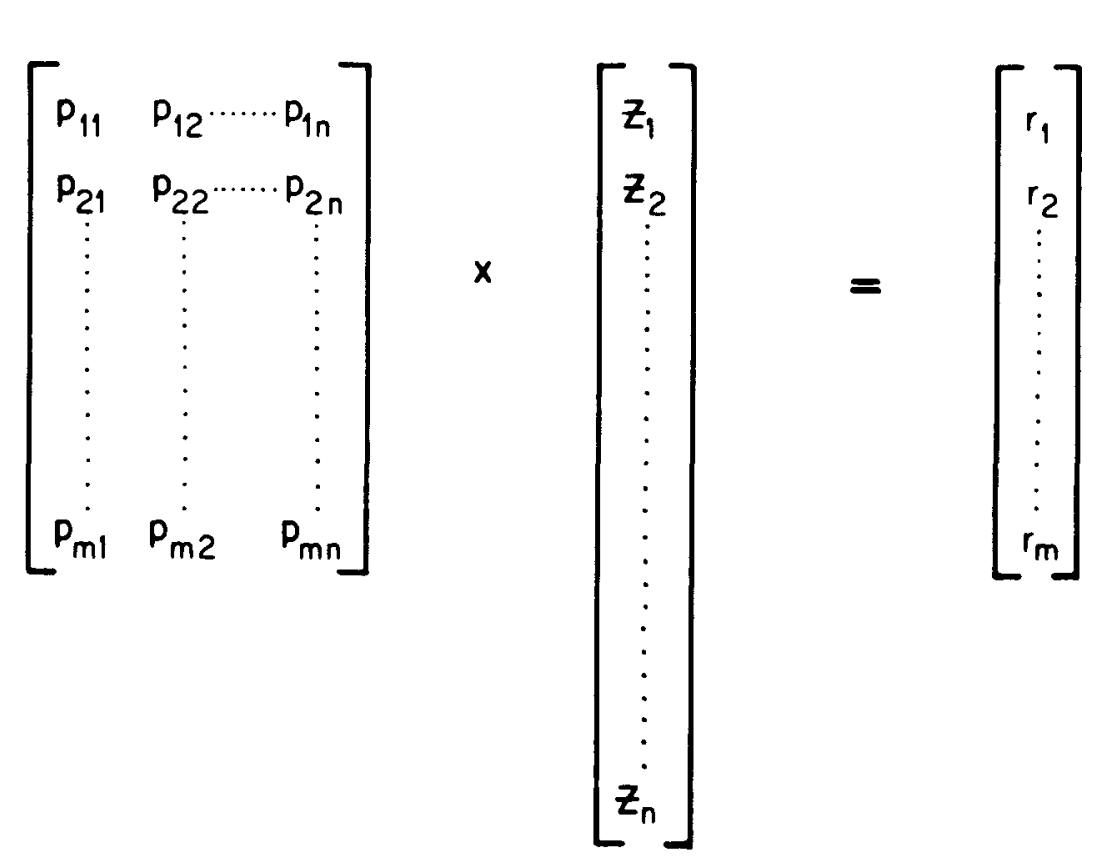

Fig. 1. MPM pattern recognition methodology. 
$z^{\prime}$ values will become positive (which implies that the predicted value exceeds the measured value) or negative (which implies the opposite). Nonzero elements of any particular row of $\mathbf{P}$ are chosen to correspond to the expected nonzero elements of $\mathbf{Z}$ that are associated with a certain class of events.

As defined in Eq. (1), each $z^{\prime}$ statistic can assume any value between positive and negative infinity. This continuum of allowable $z^{\prime}$ values makes it impossible to consistently associate a unique $r$ value with the occurrence of a specific process event. That is, no matter what values are selected for the $p$ elements, many combinations of $z$ values will yield a particular $r$ value. In the initial application of MPM, this problem has been solved by quantizing the raw $z^{\prime}$ statistics. A new variable, called $z_{i}$, is defined by partitioning the range of $z_{i}^{\prime}$ into three regions:

$$
z_{i}=\begin{array}{rll}
-1 & \text { if } & z_{i}^{\prime}<-\mathrm{k} \\
0 & \text { if } & -\mathrm{k} \leqslant z_{i}^{\prime} \leqslant \mathrm{k} \\
+1 & \text { if } \quad & z_{i}^{\prime}>\mathrm{k}
\end{array}
$$

where $\mathrm{k}$ is a constant that arbitrarily set equal to three.

Two steps are now required to choose elements for the pattern matrix. First, it must be determined which elements should be assigned nonzero values. Nonzero elements for a particular row in $\mathbf{P}$ are selected to correspond to those elements in $\mathbf{Z}$ that are expected to deviate substantially from zero upon the occurrence of a specific process event. The second step in choosing pattern matrix elements is to select an integral value for each nonzero element. Currently, the value is assigned according to the formula:

$$
p_{i j}=3^{\mathrm{k}}\left(\mathrm{k}=0,1,2, \ldots, q_{i}\right)
$$

for

$$
j=1,2, \ldots, n,
$$

and

$$
q_{i}-1 \leqslant n
$$

is the total number of nonzero elements in row $i$. With the $z$ statistics quantized to three possible values, the selection of $p$ elements according to Eq. (4) will guarantee that each combination of $z$ 's will generate a unique $r$.

Consider the following hypothetical example. When a specific process event occurs, such as a batch transfer between two tanks, certain $z$ statistics may be expected to become positive and certain ones negative:

$$
\begin{aligned}
& z_{1}=0 \\
& z_{2}=-1 \\
& z_{3}=-1 \\
& z_{4}=0 \\
& z_{5}=+1
\end{aligned}
$$


This pattern of $z$ 's will correspond to Event A. It is entirely possible that the same five $z$ 's may assume a different set of values when some other event occurs. For example:

$$
\begin{aligned}
& z_{1}=0 \\
& z_{2}=+1 \\
& z_{3}=-1 \\
& z_{4}=0
\end{aligned} \quad \text { Event B } \quad \begin{aligned}
& z_{1}=-1 \\
& z_{2}=-1 \\
& z_{5}=+1
\end{aligned} \quad \begin{aligned}
& z_{3}=0 \\
& z_{4}=0 \\
& z_{5}=+1
\end{aligned} \quad \text { Event C }
$$

To uniquely identify each of these events, the following elements would be selected for one row of the pattern matrix:

\section{$\begin{array}{lllll}1 & 3 & 9 & 27 & 81\end{array}$}

Thus, when Event A occurs, the $r$ value obtained is:

$$
\begin{aligned}
r_{A} & =(0 \cdot 1)+(-1 \cdot 3)+(-1 \cdot 9)+(0 \cdot 27)+(1 \cdot 81) \\
& =69 .
\end{aligned}
$$

Similarly,

$$
\begin{aligned}
r_{B} & =(0 \cdot 1)+(1 \cdot 3)+(-1 \cdot 9)+(0 \cdot 27)+(1 \cdot 81) \\
& =75
\end{aligned}
$$

and

$$
\begin{aligned}
r_{C} & =(-1 \cdot 1)+(-1 \cdot 3)+(0 \cdot 9)+(0 \cdot 27)+(1 \cdot 81) \\
& =77
\end{aligned}
$$

By choosing these pattern matrix elements, any combination of five quantized $z$ values will generate a unique, integral value for $r$. Now it is possible to assign to a specific integral value of $r$ a written message describing each foreseeable process event. Another example of this procedure is discussed at the end of Sect. 3. Each element in $r$ could, in theory, assume any of $3^{n}$ unique values, one for each possible combination of $z$ 's. However, most $z$ combinations are not assignable to specific process events, and in practice a more limited range of $r$ values is observed. Because $n$ is large in the current application of MPM, $\mathbf{Z}$ and $\mathbf{P}$ have been partitioned into subsets representing classes of similar events. 
$2-6$

-

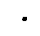

-

•

- 


\section{MPM EXPERIMENTS AT THE BARNWELL NUCLEAR FUEL PLANT}

\subsection{Brief Description of the BNFP}

During the spring and summer of 1980, the MPM concept was tested at the BNFP in Barnwell, South Carolina. The availability of the facility offered an excellent opportunity to apply MPM to reprocessing data in a realistic industrial environment. The BNFP is a Purex-type reprocessing plant designed to handle $1500 \mathrm{t}$ of heavy metal feed per year. The plant has never been licensed to process spent nuclear fuel; however, cold operation with natural uranium has been successfully demonstrated. ${ }^{22}$ For the MPM experiments, the plutonium extraction and purification cycles of the BNFP were operated with natural uranium feed solution for four 7-d periods. These periods will henceforth be referred to as miniruns.

\subsubsection{Process layout and operation}

The plutonium extraction and purification system of the BNFP consists of five solvent extraction columns, seven tanks, and a concentrator (see Fig. 2). Piping was changed to permit recycle of uranium from the storage tanks to the $1 \mathrm{BP}$ surge tank. The second and

ORNL DWG 81-1365R

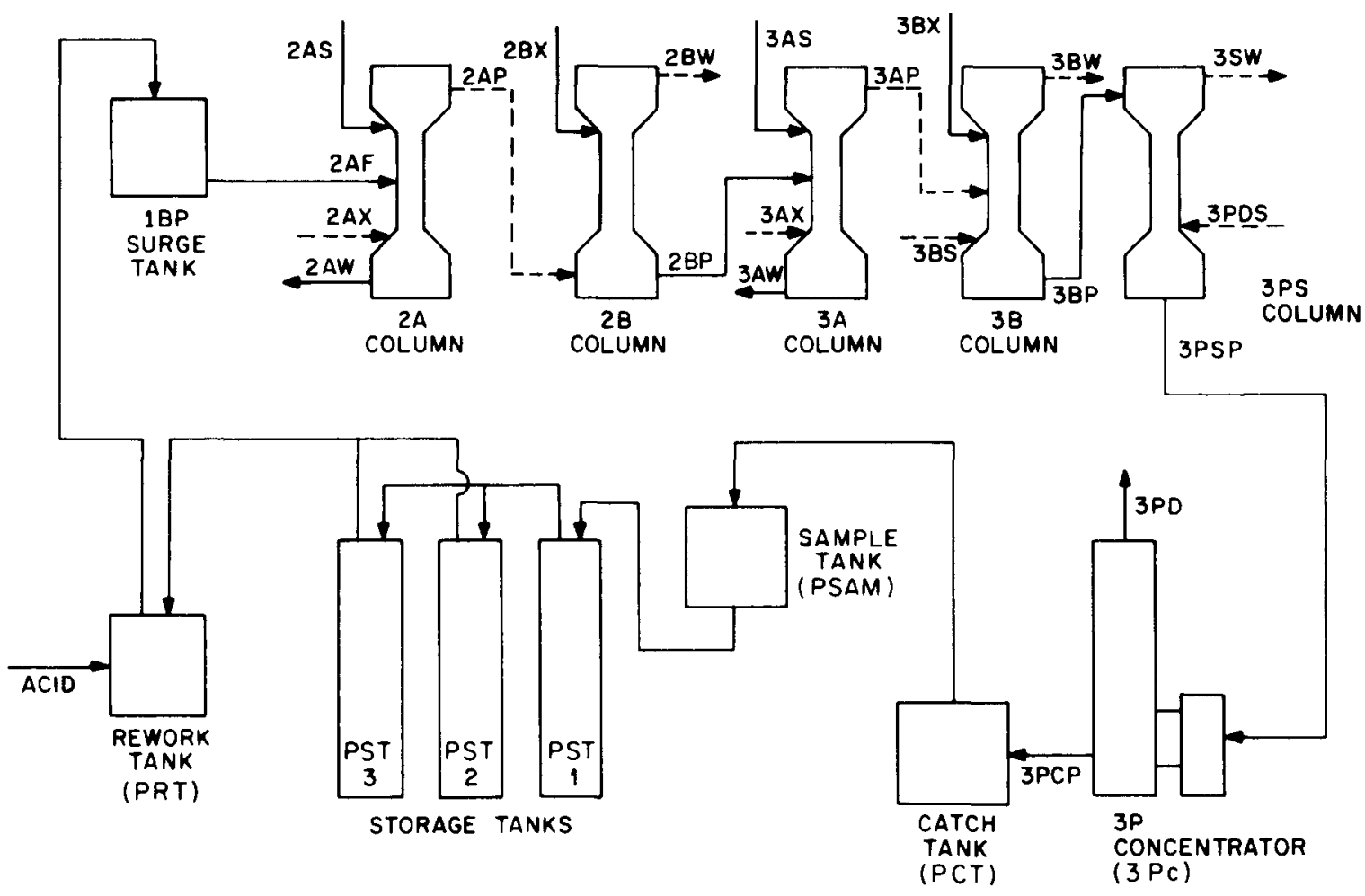

Fig. 2. Process equipment used in the BNFP demonstration of MPM. 
third cycles of the plutonium extraction and purification system each have an extraction column and a stripping column. The system also has a diluent wash column (3PS) in which tributyl phosphate is stripped from the aqueous product stream.

For each minirun, an initial charge of $300 \mathrm{~g} / \mathrm{L}$ uranyl nitrate was placed in the storage tanks. Normally, no additional uranium is added during the $7-\mathrm{d}$ period, and none is removed except for experimental diversions and unintentional losses from the pulse columns. In steady-state operation, 200- to 300-L batches of concentrated uranyl nitrate were transferred into the rework tank about every $12 \mathrm{~h}$ and blended with 700 to $800 \mathrm{~L}$ of $3 \mathrm{M}$ nitric acid. The resulting solution was subsequently transferred to the $1 \mathrm{BP}$ surge tank; from there, it was continuously fed into the $2 \mathrm{~A}$ column. The dilute uranium solution flowed continuously through the five columns and into the $3 \mathrm{P}$ concentrator. There the uranyl nitrate was concentrated from about $50 \mathrm{~g} / \mathrm{L}$ back to the original $300 \mathrm{~g} / \mathrm{L}$. The concentrated solution flowed continuously into the catch tank. Batches of about 40 to $50 \mathrm{~L}$ were transferred from the catch tank to the sample tank every 2 or $3 \mathrm{~h}$. After a few batches accumulated in the sample tank, the solution was transferred to the first storage tank. From there, the liquid was transferred to either the second or third storage tank to await reblending in the rework tank.

\subsubsection{Process measurement instruments}

The plutonium extraction and purification systems at the BNFP are equipped with standard radiochemical process instrumentation. Solution level and density are measured in each tank by purged dip-tube, differential-pressure instruments. In this type of instrument, three open-ended tubes are installed in the vessel of interest, as shown in Fig. 3. The tube lengths are arranged so that one of them reaches close to the bottom of the vessel, one stops a few centimeters higher, and one stops above the highest possible solution level. Since it is never submerged, the air pressure in the third, or reference probe, is the same as the prevailing pressure in the process vessel. The air pressure in the other two probes is equal to the prevailing reference pressure plus the hydrostatic pressure corresponding to their respective depths. If the cross-sectional area of each probe is the same, the difference in air pressures experienced by the two deep probes is proportional to their vertical separation and the solution density. The vertical separation is known, so the differential pressure $\Delta p_{1}$ can be used to measure solution density, as indicated by the density equation in Fig. 3 . Once the density is known, the solution level can be inferred from the pressure difference between the deepest probe and the reference probe. The equation relating level and $\Delta p_{2}$ is also given in Fig. 3. The volume of solution in the tank is calculated from a predetermined calibration curve relating level and volume.

Purged dip-tube instruments are uncomplicated and can, under some circumstances, attain precisions of $1 \%$ or better. ${ }^{10,22}$ They do, however, have some disadvantages that can degrade their value for process monitoring. One problem is a tendency for uranium salts to precipitate at the tube openings and bias the measured pressure differences. Another is the unreliability of the measurements when the solution density is not constant throughout the vessel. These situations were frequently encountered during the MPM experiments, and their effects will be discussed in Sect. 4 .

The pulsed columns were also equipped with dip-tube instruments for measuring top levels, top densities, interface positions, and bulk solution weight. Out-of-cell rotameters were used to measure most pulsed-column extractant and scrub stream flow rates. The only 


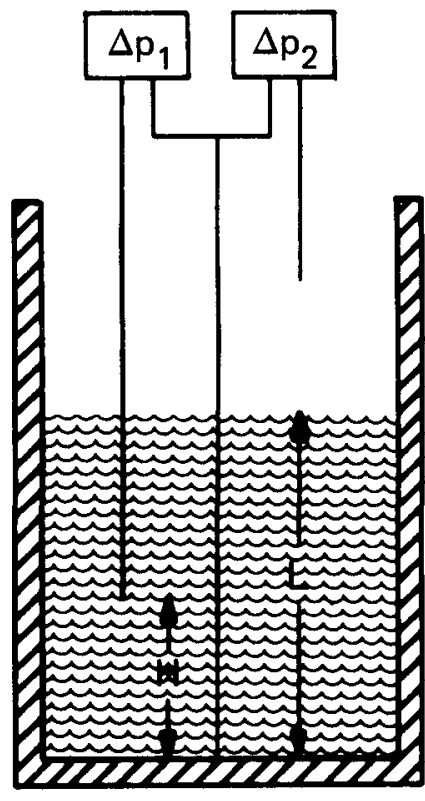

\author{
$H=$ FIXED DISTANCE BETWEEN DEEP PROBES \\ $L=$ LIQUID LEVEL \\ $D=$ SOLUTION DENSITY \\ $g=$ GRAVITATIONAL CONSTANT
}

DENSITY EQUATION:

$$
\begin{gathered}
\Delta \mathrm{p}_{1}=\mathrm{HDg} \\
\mathrm{D}=\frac{\Delta \mathrm{p}_{1}}{\mathrm{Hg}}
\end{gathered}
$$

LEVEL EQUATION:

$$
\begin{gathered}
\Delta p_{2}=L D g \\
L=\frac{\Delta p_{2}}{D g}=\frac{\Delta p_{2} H}{\Delta p_{1}}
\end{gathered}
$$

Fig. 3. Purged dip-tube level and density measurement.

flow rate measurement available on the main process stream was from a metering head-pot located between the $1 \mathrm{BP}$ surge tank and the $2 \mathrm{~A}$ column. The nitric acid concentration of the same stream was measured to permit application of an empirical relationship between acid concentration, solution density, and uranium concentration. Alpha monitors were located on most pulsed-column waste streams.

Table 1 summarizes the 52 measurements used for the MPM experiments. The two right-hand columns contain uncertainty factors for the measurements. Column 1 contains 
Table 1. Measurements used for the MPM experiments at the BNFP

\begin{tabular}{|c|c|c|c|c|}
\hline \multirow{2}{*}{ Parameter type } & \multirow{2}{*}{ Location } & \multirow{2}{*}{ Average value } & \multicolumn{2}{|c|}{ Uncertainty factors } \\
\hline & & & 1 & 2 \\
\hline Tank level & $\begin{array}{l}\text { Rework tank } \\
\text { 1BP surge tank } \\
\text { Catch tank } \\
\text { Sample tank } \\
\text { Storage tank } 1 \\
\text { Storage tank } 2 \\
\text { Storage tank } 3 \\
\text { 3P concentrator }\end{array}$ & $\begin{array}{r}125 \mathrm{~cm} \\
90 \mathrm{~cm} \\
35 \mathrm{~cm} \\
50 \mathrm{~cm} \\
100 \mathrm{~cm} \\
100 \mathrm{~cm} \\
100 \mathrm{~cm} \\
80 \mathrm{~cm}\end{array}$ & $\begin{array}{l}0.08 \mathrm{~cm} \\
6.0 \mathrm{~cm} \\
1.0 \mathrm{~cm} \\
0.04 \mathrm{~cm} \\
0.05 \mathrm{~cm} \\
0.02 \mathrm{~cm} \\
0.13 \mathrm{~cm} \\
2.60 \mathrm{~cm}\end{array}$ & $\begin{array}{l}0.12 \mathrm{~cm} \\
1.25 \mathrm{~cm} \\
1.0 \mathrm{~cm} \\
0.11 \mathrm{~cm} \\
0.10 \mathrm{~cm} \\
0.05 \mathrm{~cm} \\
0.13 \mathrm{~cm} \\
2.60 \mathrm{~cm}\end{array}$ \\
\hline Tank density & $\begin{array}{l}\text { Rework tank } \\
\text { 1BP surge tank } \\
\text { Catch tank } \\
\text { Sample tank } \\
\text { Storage tank } 1 \\
\text { Storage tank } 2 \\
\text { Storage tank } 3 \\
\text { 3P concentrator }\end{array}$ & $\begin{array}{l}1.16 \mathrm{~g} / \mathrm{mL} \\
1.16 \mathrm{~g} / \mathrm{mL} \\
1.44 \mathrm{~g} / \mathrm{mL} \\
1.44 \mathrm{~g} / \mathrm{mL} \\
1.44 \mathrm{~g} / \mathrm{mL} \\
1.44 \mathrm{~g} / \mathrm{mL} \\
1.44 \mathrm{~g} / \mathrm{mL} \\
1.40 \mathrm{~g} / \mathrm{mL}\end{array}$ & $\begin{array}{l}0.001 \mathrm{~g} / \mathrm{mL} \\
0.001 \mathrm{~g} / \mathrm{mL} \\
0.001 \mathrm{~g} / \mathrm{mL} \\
0.002 \mathrm{~g} / \mathrm{mL} \\
0.001 \mathrm{~g} / \mathrm{mL} \\
0.001 \mathrm{~g} / \mathrm{mL} \\
0.002 \mathrm{~g} / \mathrm{mL} \\
0.015 \mathrm{~g} / \mathrm{mL}\end{array}$ & $\begin{array}{l}0.002 \mathrm{~g} / \mathrm{mL} \\
0.011 \mathrm{~g} / \mathrm{mL} \\
0.012 \mathrm{~g} / \mathrm{mL} \\
0.012 \mathrm{~g} / \mathrm{mL} \\
0.007 \mathrm{~g} / \mathrm{mL} \\
0.003 \mathrm{~g} / \mathrm{mL} \\
0.004 \mathrm{~g} / \mathrm{mL} \\
0.012 \mathrm{~g} / \mathrm{mL}\end{array}$ \\
\hline Flow rate & $\begin{array}{c}2 \mathrm{AX} \\
2 \mathrm{AS} \\
2 \mathrm{BX} \\
3 \mathrm{AX} \\
3 \mathrm{AS} \\
2 \mathrm{BP} \text { acid } \\
3 \mathrm{BX} \\
2 \mathrm{AF}\end{array}$ & $\begin{array}{l}102 \mathrm{~L} / \mathrm{h} \\
62 \mathrm{~L} / \mathrm{h} \\
258 \mathrm{~L} / \mathrm{h} \\
80 \mathrm{~L} / \mathrm{h} \\
19.5 \mathrm{~L} / \mathrm{h} \\
80 \mathrm{~L} / \mathrm{h} \\
93 \mathrm{~L} / \mathrm{h} \\
100 \mathrm{~L} / \mathrm{h}\end{array}$ & $\begin{array}{c}0.03 \mathrm{~L} / \mathrm{h} \\
0.07 \mathrm{~L} / \mathrm{h} \\
0.20 \mathrm{~L} / \mathrm{h} \\
0.05 \mathrm{~L} / \mathrm{h} \\
0.02 \mathrm{~L} / \mathrm{h} \\
0.12 \mathrm{~L} / \mathrm{h} \\
0.20 \mathrm{~L} / \mathrm{h} \\
37.0 \mathrm{~L} / \mathrm{h}\end{array}$ & $\begin{array}{l}0.25 \mathrm{~L} / \mathrm{h} \\
0.12 \mathrm{~L} / \mathrm{h} \\
0.73 \mathrm{~L} / \mathrm{h} \\
0.43 \mathrm{~L} / \mathrm{h} \\
0.18 \mathrm{~L} / \mathrm{h} \\
0.60 \mathrm{~L} / \mathrm{h} \\
0.20 \mathrm{~L} / \mathrm{h} \\
0.87 \mathrm{~L} / \mathrm{h}\end{array}$ \\
\hline Column top level & $\begin{array}{c}2 \mathrm{~A} \\
3 \mathrm{~A} \\
3 \mathrm{~B} \\
3 \mathrm{PS}\end{array}$ & $\begin{array}{r}13.3 \mathrm{in.} \\
13.9 \mathrm{in.} \\
12.5 \mathrm{in.} \\
0.1 \mathrm{in.}\end{array}$ & $\begin{array}{l}1.0 \text { in. } \\
0.90 \text { in. } \\
0.26 \text { in. } \\
0.70 \text { in. }\end{array}$ & $\begin{array}{l}1.0 \mathrm{in.} \\
0.90 \mathrm{in} . \\
0.26 \mathrm{in.} \\
0.70 \mathrm{in} .\end{array}$ \\
\hline $\begin{array}{l}\text { Column interface } \\
\text { level }\end{array}$ & $\begin{array}{c}2 \mathrm{~A} \\
2 \mathrm{~B} \\
3 \mathrm{~A} \\
3 \mathrm{~B} \\
3 \mathrm{PS}\end{array}$ & $\begin{array}{r}21.5 \mathrm{in} . \\
9.1 \mathrm{in} . \\
21.0 \mathrm{in} . \\
9.1 \mathrm{in} . \\
20.9 \mathrm{in} .\end{array}$ & $\begin{array}{l}0.70 \mathrm{in} . \\
0.05 \mathrm{in} . \\
0.51 \mathrm{in} . \\
0.01 \mathrm{in} . \\
0.05 \mathrm{in} .\end{array}$ & $\begin{array}{l}1.0 \mathrm{in.} \\
0.20 \mathrm{in} . \\
0.90 \mathrm{in} . \\
0.26 \mathrm{in} . \\
0.70 \mathrm{in} .\end{array}$ \\
\hline Column top density & $\begin{array}{c}2 \mathrm{~A} \\
2 \mathrm{~B} \\
3 \mathrm{~A} \\
3 \mathrm{~B} \\
3 \mathrm{PS}\end{array}$ & $\begin{array}{l}0.92 \mathrm{~g} / \mathrm{mL} \\
0.83 \mathrm{~g} / \mathrm{mL} \\
0.89 \mathrm{~g} / \mathrm{mL} \\
0.84 \mathrm{~g} / \mathrm{mL} \\
0.66 \mathrm{~g} / \mathrm{mL}\end{array}$ & $\begin{array}{l}0.003 \mathrm{~g} / \mathrm{mL} \\
0.003 \mathrm{~g} / \mathrm{mL} \\
0.002 \mathrm{~g} / \mathrm{mL} \\
0.002 \mathrm{~g} / \mathrm{mL} \\
0.001 \mathrm{~g} / \mathrm{mL}\end{array}$ & $\begin{array}{l}0.01 \mathrm{~g} / \mathrm{mL} \\
0.01 \mathrm{~g} / \mathrm{mL} \\
0.01 \mathrm{~g} / \mathrm{mL} \\
0.01 \mathrm{~g} / \mathrm{mL} \\
0.01 \mathrm{~g} / \mathrm{mL}\end{array}$ \\
\hline Column bulk weight & $\begin{array}{c}2 \mathrm{~A} \\
2 \mathrm{~B} \\
3 \mathrm{~A} \\
3 \mathrm{~B} \\
3 \mathrm{PS}\end{array}$ & $\begin{array}{l}465 \mathrm{~kg} \\
360 \mathrm{~kg} \\
420 \mathrm{~kg} \\
555 \mathrm{~kg} \\
110 \mathrm{~kg}\end{array}$ & $\begin{array}{r}6.0 \mathrm{~kg} \\
4.6 \mathrm{~kg} \\
7.5 \mathrm{~kg} \\
14.0 \mathrm{~kg} \\
0.8 \mathrm{~kg}\end{array}$ & $\begin{array}{r}6.0 \mathrm{~kg} \\
4.6 \mathrm{~kg} \\
7.5 \mathrm{~kg} \\
14.0 \mathrm{~kg} \\
0.8 \mathrm{~kg}\end{array}$ \\
\hline
\end{tabular}


Table 1. (continued)

\begin{tabular}{lcccc}
\hline \multirow{2}{*}{ Parameter type } & Location & Average value & \multicolumn{2}{c}{ Uncertainty factors } \\
\cline { 4 - 5 } & & & 1 & 2 \\
\hline \multirow{2}{*}{ Alpha count } & $2 \mathrm{AW}$ & $0.3 \mathrm{cpm}$ & $\mathrm{NA}$ & $0.8 \mathrm{cpm}$ \\
& $2 \mathrm{BW}$ & $0.4 \mathrm{cpm}$ & $\mathrm{NA}$ & $3.0 \mathrm{cpm}$ \\
& $3 \mathrm{AW}$ & $0.8 \mathrm{cpm}$ & $\mathrm{NA}$ & $3.0 \mathrm{cpm}$ \\
& $3 \mathrm{BW}$ & $8.0 \mathrm{cpm}$ & $\mathrm{NA}$ & $1.3 \mathrm{cpm}$ \\
& $3 \mathrm{PD}$ & $90 \mathrm{cpm}$ & $\mathrm{NA}$ & $3.0 \mathrm{cpm}$ \\
$\mathrm{HNO}_{3}$ concentration & $2 \mathrm{AS}$ & $1.16 \mathrm{~m}$ & $0.001 \mathrm{~m}$ & $0.02 \mathrm{~m}$ \\
& $3 \mathrm{AS}$ & $0.70 \mathrm{~m}$ & $0.001 \mathrm{~m}$ & $0.01 \mathrm{~m}$ \\
& $2 \mathrm{BX}$ & $0.08 \mathrm{~m}$ & $0.001 \mathrm{~m}$ & $0.002 \mathrm{~m}$ \\
& $1 \mathrm{BP}$ surge tank & $3.12 \mathrm{~m}$ & $0.001 \mathrm{~m}$ & $0.036 \mathrm{~m}$ \\
\hline
\end{tabular}

estimates of the imprecision of each measurement based on data from the first minirun. The values were obtained by calculating the standard deviation of at least 25 consecutive measurements, taken at 4-min intervals. The consecutive measurements were selected from time periods during which the amount of variation in the parameters appeared to be typical. Each uncertainty factor has the same units as the measured parameter to which it corresponds.

The column 1 uncertainties provided reasonable initial values for all of the $s_{y}$ variables discussed in Sect. 2. As the experiments progressed, the measurement uncertainties were frequently altered to improve the response of MPM to various process events. One of the advantages of the MPM methodology is that changes in individual uncertainties can be made quickly through an on-line terminal. Since the uncertainties control the sensitivity of MPM to any specific process phenomenon, such adjustments can be used to tune MPM's response. The uncertainties in column 2 of Table 1 were in use at the end of minirun four. Some of the measurements were not used extensively during the first four minirun experiments. In these cases, the column 1 and column 2 uncertainties are probably the same. For heavily used measurements, the column 2 uncertainties represent a set of values that permitted improved MPM performance.

The column 2 uncertainty factors were arrived at empirically, not analytically. For that reason, they do not constitute a unique or mathematically optimal set. Nor can they be strictly interpreted in conventional statistical terms as accuracy or precision estimates. They are factors used to normalize observed discrepancies between predicted and measured parameter values. Throughout the MPM experiments, these factors were adjusted to increase MPM's sensitivity to important process events and to decrease its sensitivity to unimportant ones. This tuning process will be continued as the BNFP data are evaluated in more detail. The adjustment of individual uncertainty factors in response to various process conditions is discussed in Sect. 4.

\subsection{Data Acquisition and Handling}

The data flow for the MPM experiments at the BNFP is shown in Fig. 4. The process sensors generate electronic analogue signals, which are transmitted to the control room for 


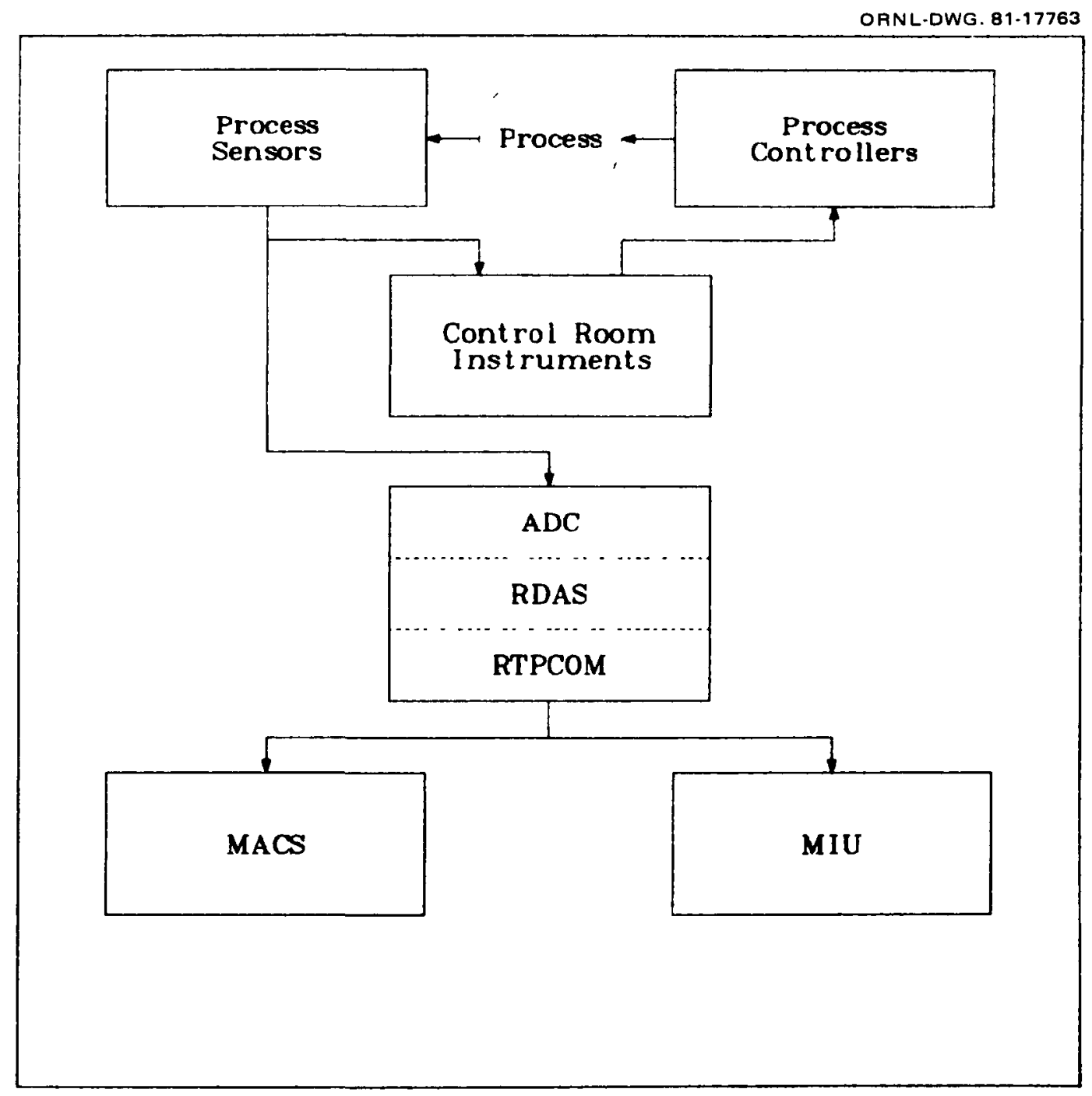

Fig. 4. Data flow for the BNFP experiment.

panel display and to a digital computer system through analogue-to-digital converters. The digital data are scanned by a PDP-11/34 computer, called the Remote Data Acquisition System (RDAS), and converted to physical units, usually inches of water. These data are then stored in the RDAS memory until new data are available. A program resident in the RDAS computer, called RTPCOM, makes the stored data available to two PDP-11/34 computers, the Material Accounting and Control System (MACS) computer and the Management Information Unit (MIU) computer. The MPM programs were installed on the MIU computer. It is worth noting that no information flows between the MIU computer and the process controllers, and that the MPM programs therefore have no direct knowledge of actions taken by the process operators. The MPM's performance would certainly improve if such information were available, and provisions should be made to obtain this information in future applications.

Each instrument continuously generates an analogue voltage signal, which is multiplexed into an analogue-to-digital converter. Figure 5 illustrates a typical analogue signal 


\section{ANALOGUE SIGNAL FROM A PROCESS INSTRUMENT}

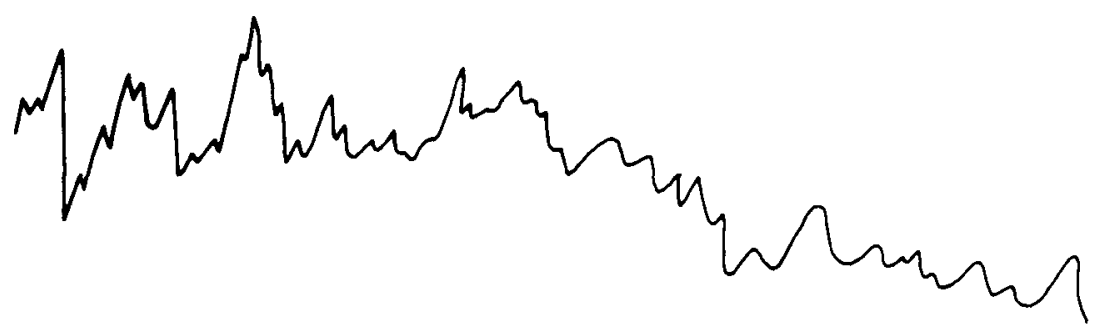

DIGITIZED SIGNAL FROM A PROCESS INSTRUMENT

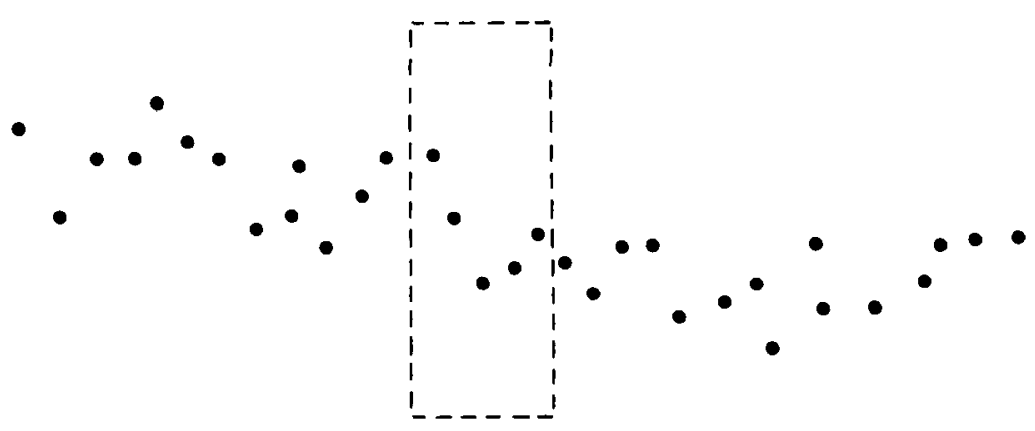

Fig. 5. Data acquisition modes.

and its digital equivalent. The value assigned by the RDAS computer to any particular measurement is usually an average of several digitized readings. The number of readings averaged (indicated in Fig. 5 by the dashed box), is determined by the expected steadiness of the parameter in question. For a widely oscillating measurement, a larger number of readings would be averaged. The RTPCOM program transmits a new value for each measurement to the MIU computer every $4 \mathrm{~min}$.

Figure 6 is a flow chart of the MPM computer program. When the RTPCOM program has completed the transmission of fresh data to the MIU computer, an interrupt is issued and the MPM task is executed. Raw data is read into the program and converted from inches of water to engineering units. The conversion tables and computer programs used to accomplish this task are process specific and were provided by the BNFP staff. The newly converted data are used to update the $z$ values and are written on direct access disk for longterm storage. Current data are also placed in computer memory for short-term storage along with measurements made 4 and $8 \mathrm{~min}$ earlier. The disk files can be accessed by peripheral programs to provide data listings and graphs. Pattern matrices are read in from direct access disk and are combined with the $z$ 's to generate the MPM messages. Once the messages are printed, the MPM program task is written on direct access disk from core and remains 
ORNL-DWG. 81-17764

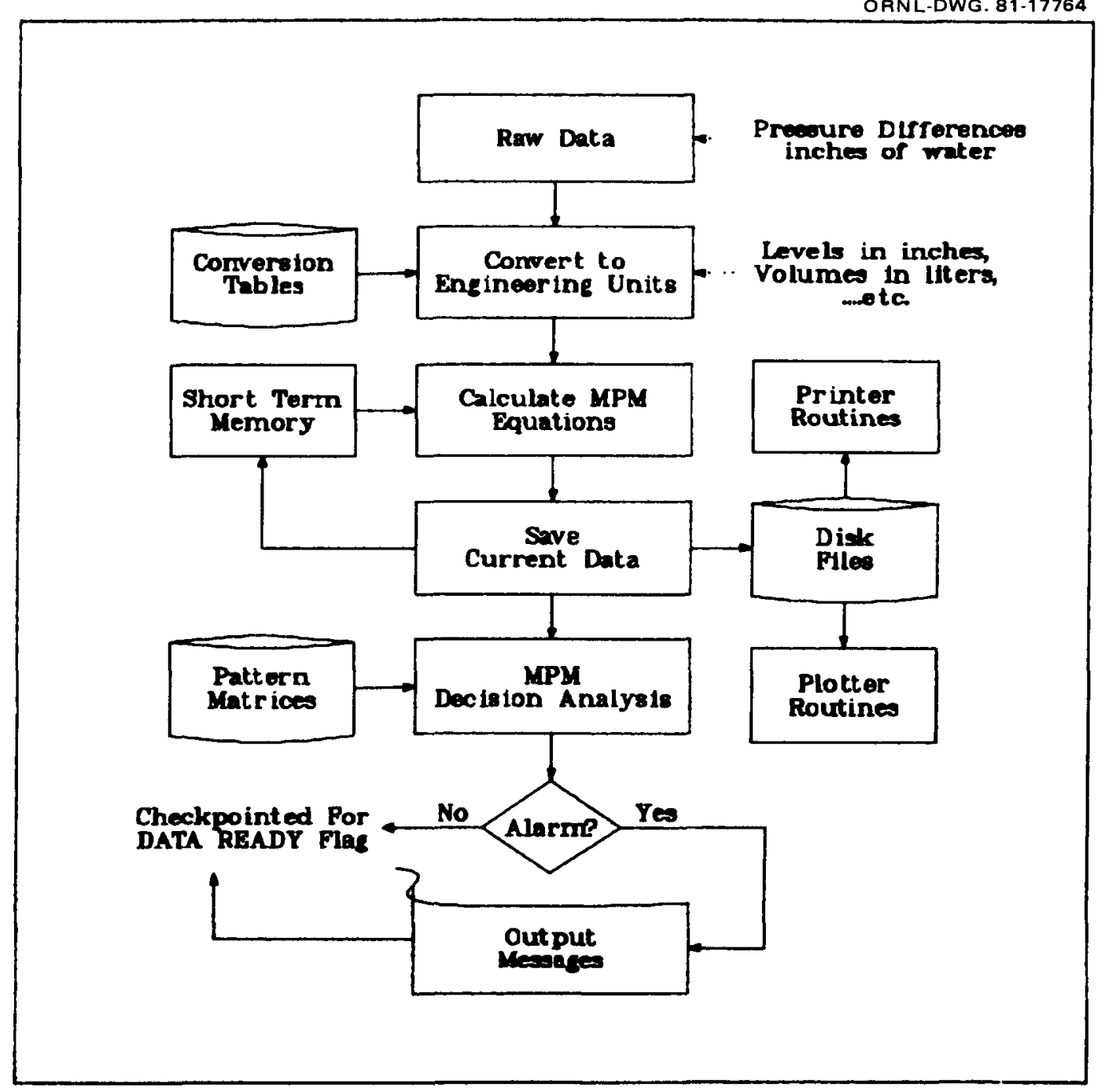

Fig. 6. Flow chart for the MPM computer program.

inactive until the arrival of new data. This frees the 32 kilobytes of core used by the program for about 3 out of every $4 \mathrm{~min}$.

In general, nothing about the computer resources available at the BNFP is special. The types of minicomputers and data transmission hardware used are standard equipment at modern chemical processing plants. One of the important purposes of the BNFP experiment was to demonstrate that MPM can be successfully implemented on a standard process control minicomputer system in an industrial environment.

\subsection{Prediction Equations}

Microscopic process monitoring compares measured values of process variables with predicted values. For the Barnwell experiments, the measured values were updated in the data base at 4-min intervals. A predicted value (sometimes more than one) for each measure- 
ment was also calculated every $4 \mathrm{~min}$. Two types of equations were used to generate the predictions: extrapolation equations and conservation equations.

Extrapolation equations are simple in principle. They are based on the assumption that past trends will continue. Only linear extrapolations were used for the FY 1980 MPM experiments. A typical example is shown in Fig. 7. The predicted value of a variable is set equal to the old value plus the difference between the last two measurements. Prediction equations of the type indicated in Fig. 7 were written for every measured variable.

Conservation equations describe the relationships between different process variables. These equations are based on principles of conservation of mass or, in appropriate cases, conservation of volume. By using available instrumentation and by making a series of assumptions, it is possible to write ten conservation equations for the minirun process (see Table 2). Equations (1) through (7) predict the current volume in each of the tanks

ORNL DWG $81-1362$

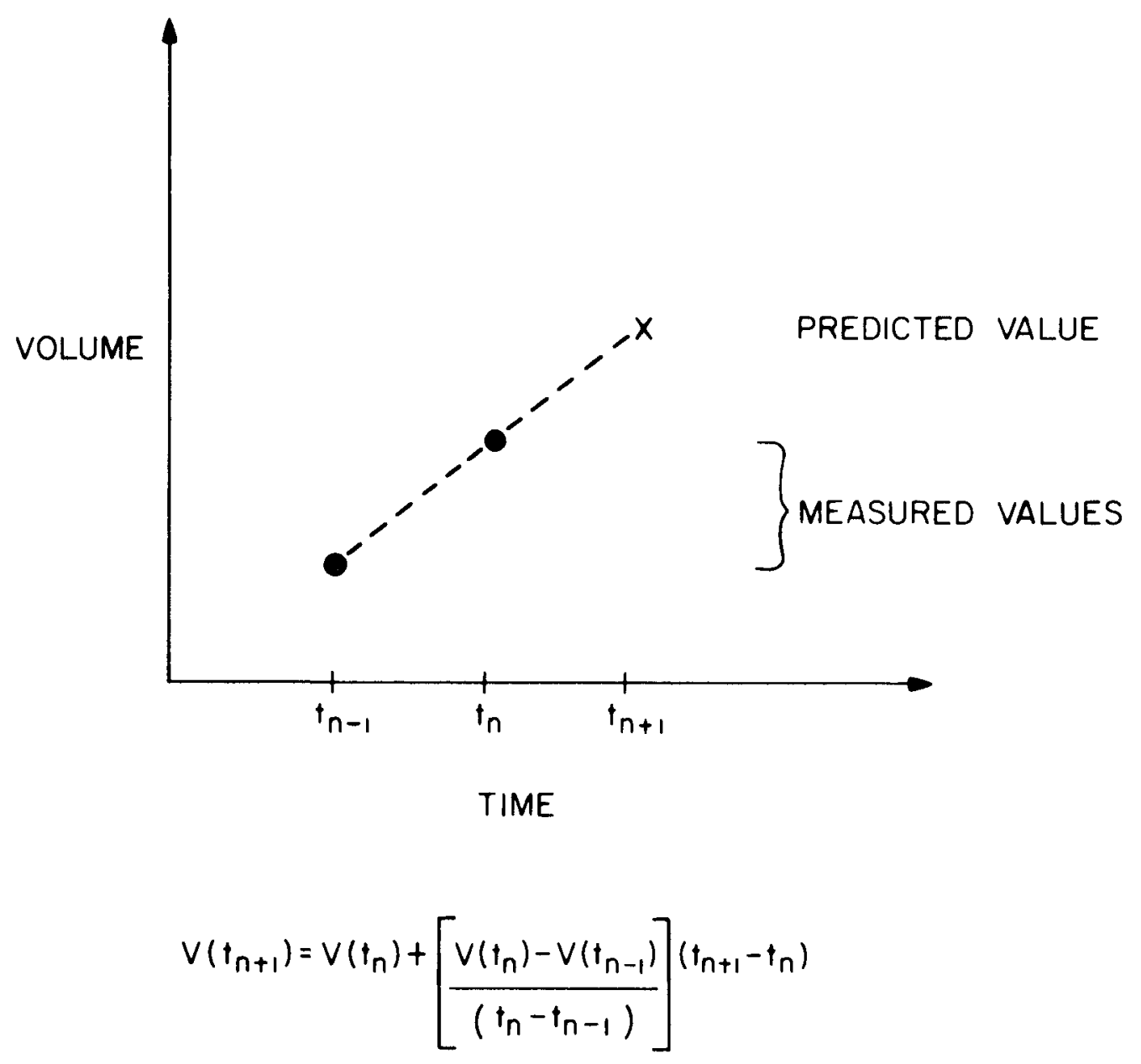

Fig. 7. Extrapolation equations. 
Table 2 FORTRAN conservation equations $s^{a}$

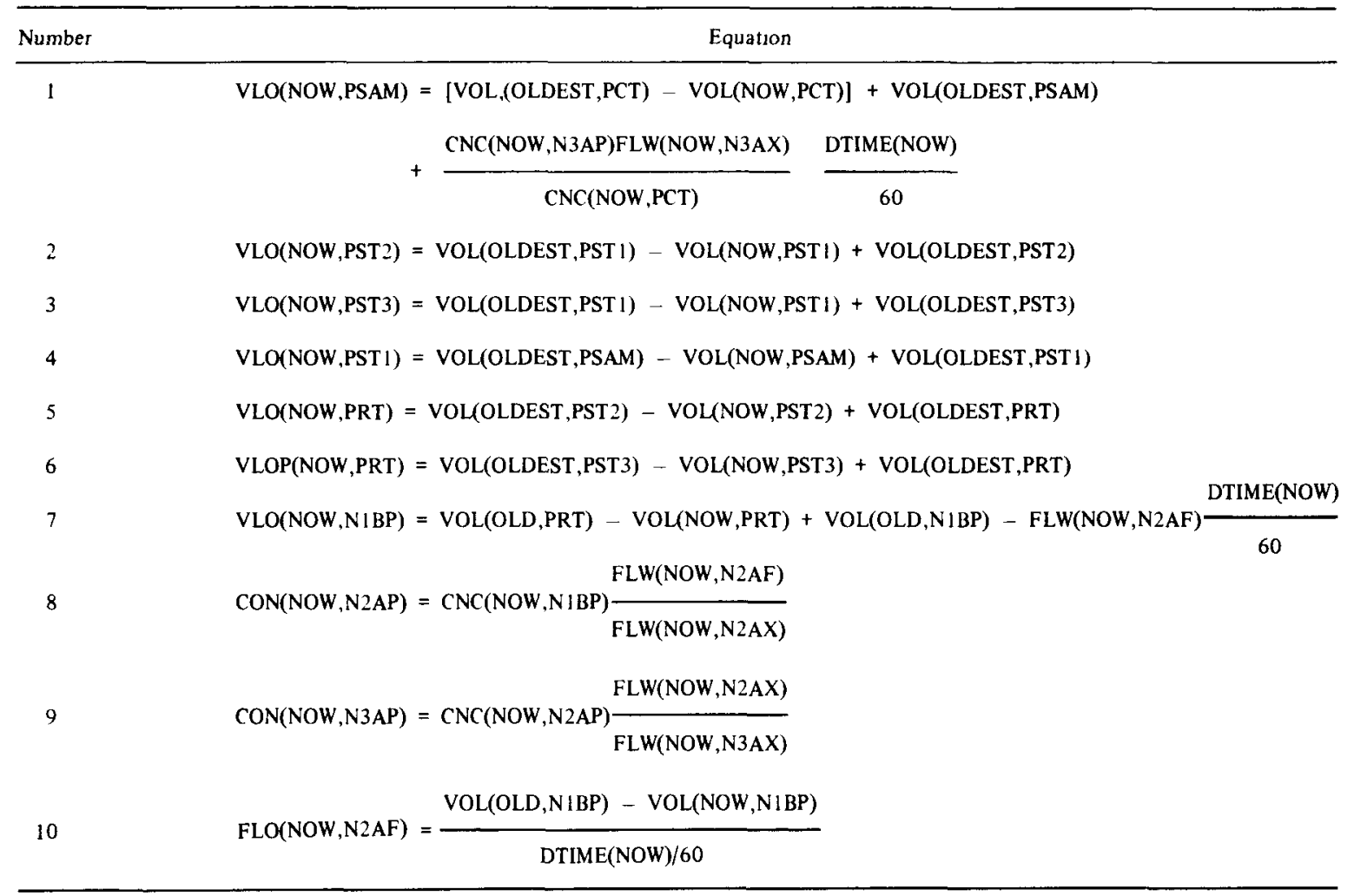

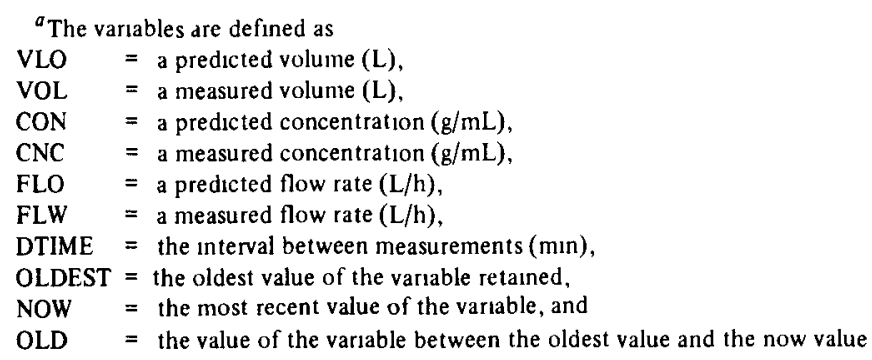

based on the volume change in the tank immediately upstream. Equations (8) and (9) predict the uranium concentration of the $2 \mathrm{~A}$ and $3 \mathrm{~A}$ product streams based on column feed concentrations and aqueous-organic flow ratios. Equation (10) predicts the $2 \mathrm{AF}$ flow rate based on the volume change in the 1BP surge tank. The terms on the right sides of these equations are measured quantities. The terms on the left sides are predictions that are compared with measurements of the same parameters to generate ten $z$ values.

\subsection{Prediction Uncertainties}

As discussed in Sect. 2, each MPM prediction must be accompanied by an uncertainty $s_{\boldsymbol{x}}$. Initial values for these uncertainties were calculated with standard error propagation formulas. For this purpose, all of the measurement errors were assumed to be mutually independent. As in the case of the measurement uncertainties, the individual prediction uncertainties were adjusted during the BNFP experiments in response to erratic or unpredictable process 
behavior. For the MPM equations, the prediction uncertainties tend to be several times larger than the corresponding measurement uncertainties.

\subsection{Discrepancy Patterns}

The MPM methodology identifies process events by associating them with specific patterns of discrepancies between measurement and prediction. The MPM technique used to recognize such patterns is discussed in Sect. 2. The problem of anticipating patterns that might be associated with a particular chemical process is the subject of this subsection.

One category of process events that must be identified is the batch transfer. Concentrated uranyl nitrate was continuously collected in the catch tank, and a batch was transferred to the sample tank about every $2 \mathrm{~h}$ (see Fig. 2). After a few batches were collected in the sample tank, the solution was batched to the first storage tank. From the first storage tank, the solution was alternately batched to the second and third storage tanks. At intervals of about $12 \mathrm{~h}$, one of these tanks was emptied into the rework tank. There the concentrated uranium solution was diluted with nitric acid to about 15 or $20 \%$ of its original concentration. The low-density uranium solution was transferred to the 1BP surge tank and from there continuously fed in to the $2 \mathrm{~A}$ column.

Equations (1) through (7) in Table 2 were written to describe specific batch transfers between tanks. Barring measurement error, the predictions from any one of these equations will be correct if the transfer it describes is occurring or if nothing is happening in the tanks referred to in the equation. As an example of this process, consider the hypothetical threetank system shown in Fig. 8. In this case, the goal would be to identify which transfer, if any, is occurring.

Two prediction equations would be written to describe the volume changes engendered by the two transfers:

$$
\begin{aligned}
& \hat{V}_{\mathrm{B}}\left(t_{n}\right)=V_{\mathrm{B}}\left(t_{n-1}\right)+\left[V_{\mathrm{A}}\left(t_{n-1}\right)-V_{\mathrm{A}}\left(t_{n}\right)\right], \\
& \hat{V}_{\mathrm{C}}\left(t_{n}\right)=V_{\mathrm{C}}\left(t_{n-1}\right)+\left[V_{B}\left(t_{n-1}\right)-V_{B}\left(t_{n}\right)\right] .
\end{aligned}
$$

Equation (5) predicts the volume in tank B at time $t_{n}$ by adding the measured volume in tank B at time $t_{n-1}$ to the measured change in the volume of tank A. Equation (6) predicts the volume in tank $C$ in analogous fashion. The hatted variables are predicted and the unhatted variables are measured. Two $z$ statistics would be calculated to correspond to these prediction equations:

$$
\begin{aligned}
z_{\mathrm{B}}\left(t_{n}\right)= & \frac{\hat{V}_{\mathrm{B}}\left(t_{n}\right)-V_{\mathrm{B}}\left(t_{n}\right)}{\left(\hat{S}_{\mathrm{B}}^{2}+S_{\mathrm{B}}^{2}\right)^{1 / 2}}, \\
z_{\mathrm{C}}\left(t_{n}\right)= & \frac{\hat{V}_{\mathrm{C}}\left(t_{n}\right)-V_{C}\left(t_{n}\right)}{\left(\hat{S}_{\mathrm{C}}^{2}+S_{\mathrm{C}}^{2}\right)^{1 / 2}}
\end{aligned}
$$


ORNL DWG 8I-|36IR

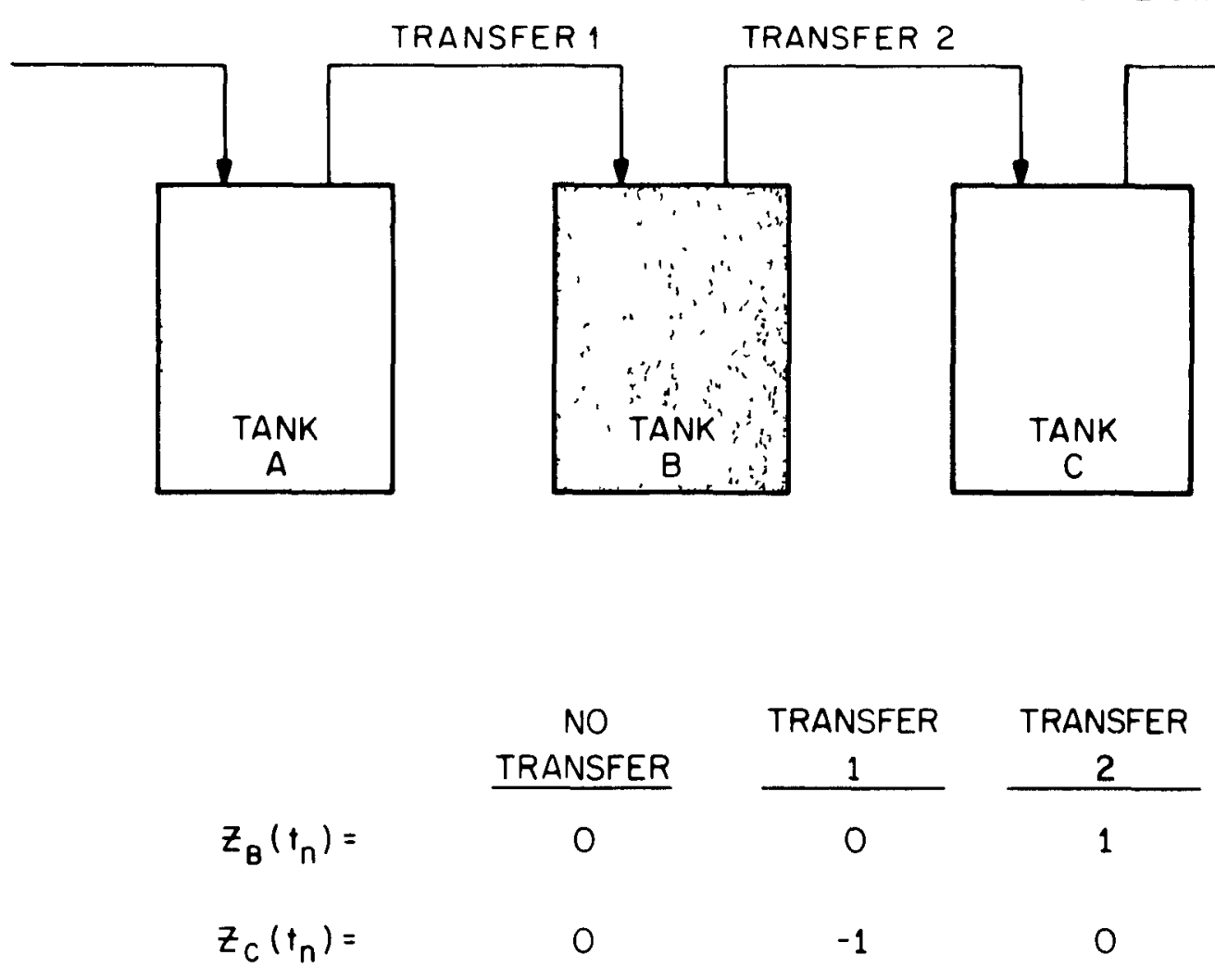

Fig. 8. Example of batch transfer identification.

The variable $\hat{S}$ is the uncertainty of the prediction, and $S$ is the uncertainty of the measurement.

Three situations are possible in this example: no transfer is occurring, transfer 1 is occurring, or transfer 2 is occurring. For simplicity, it is assumed that the two transfers cannot occur concurrently. Figure 8 illustrates the three possible combinations of $z$ statistics associated with the three situations. Recall that $z$ assumes one of three values: $-1,0$, or +1 . When no transfer has occurred during the time interval in question, the two right-hand terms in Eqs. (5) and (6) cancel, and the volume in each tank is predicted to be the same as last time. Since this corresponds to reality, the measured and predicted volumes should be roughly the same, and the $z$ statistics will be assigned values of zero. On the other hand, when transfer 1 occurs, only Eq. (5) will generate a correct prediction. Equation (6) will predict a decrease in the volume of tank $\mathrm{C}$ because the term in the brackets will be negative. In fact, the volume of tank $\mathrm{C}$ will not change when transfer 1 occurs, and $z_{C}$ will accordingly be assigned a negative value. For similar reasons, $z_{\mathrm{B}}$ will take on a positive value when transfer 2 occurs.

Two pattern matrix elements, $p_{\mathrm{B}}$ and $p_{\mathrm{C}}$, must be chosen to multiply the two $z$ 's:

$$
p_{\mathrm{B}} z_{\mathrm{B}}+p_{\mathrm{C}} z_{\mathrm{C}}=d \text {. }
$$


From Eq. (3), the values $p_{\mathrm{B}}=1$ and $p_{\mathrm{C}}=3$ would be chosen. Thus, three possible $d$ values could be generated in this example, each uniquely identifying the phenomenon at hand:

$$
\begin{array}{ll}
d=3 & \text { No transfer } \\
d=-3 & \text { Transfer } 1, \\
d=1 & \text { Transfer } 2 .
\end{array}
$$

Each $d$ value can be associated with a message describing exactly what has transpired. Other phenomena can be identified in much the same manner. The only requirement is that each phenomenon must generate a foreseeable and unique pattern of $z$ 's. The practical limitations of this technique are a major subject of Sect. 4. 


\section{EXPERIMENTAL RESULTS}

Miniruns one and two were needed to stabilize process operations and debug the data acquisition system. Serious analysis of the MPM's performance was reserved for miniruns three and four. The results described in this section were obtained on time; they are not the results that would have been obtained by analyzing taped raw data with the version of MPM in use at the end of minirun four.

\subsection{Abrupt Diversion Detection}

Controlled diversion experiments were conducted during miniruns three and four to test the abrupt diversion detection sensitivity of MPM. In minirun three, volumes of approximately $1,2,5,10$, and $20 \mathrm{~L}$ were removed from three different tanks. In minirun four, diversions of miscellaneous sizes were made from five different tanks. In all cases the solution was removed from the tanks as rapidly as possible.

\subsubsection{Minirun three diversion tests}

The second storage tank (PST2), the catch tank (PCT), and the rework tank (PRT) were used for the minirun three diversion tests. Table 3 summarizes the results of the controlled diversion experiments. Five volumes were diverted from each tank. All five diversions from PST2 were detected and correctly identified by the MPM logic. The $z$ 's associated with the diversion messages are indicated in Table 3. Not surprisingly, smaller diversions tended to generate smaller $z$ values. A $z$ threshold of 3.0 was used in minirun three; any discrepancy that generated a $z$ value between -3.0 and 3.0 did not contribute to the MPM message selection procedure. The results shown in Table 3 indicate that a diversion from PST2 substantially smaller than $1 \mathrm{~L}$ probably would not have been detected during minirun three.

Table 3. Minirun three abrupt diversion test $z$ values

\begin{tabular}{cccc}
\hline $\begin{array}{c}\text { Volume } \\
\text { diverted } \\
\text { (L) }\end{array}$ & $\begin{array}{c}\text { Storage } \\
\text { tank 2 } \\
\text { (PST2) }\end{array}$ & $\begin{array}{c}\text { Catch } \\
\text { tank } \\
\text { (PCT) }\end{array}$ & $\begin{array}{c}\text { Rework } \\
\text { tank } \\
\text { (PRT) }\end{array}$ \\
\hline 1 & 3.5 & & \\
2 & 9.4 & & \\
5 & 25 & 3.2 & $5.7^{b}$ \\
10 & 46 & 6.4 & 4.5 \\
20 & 44 & 10 & $21^{b}$ \\
\hline
\end{tabular}

${ }^{a}$ Normal'operating volumes: PST2, 170 L; PCT, 80 L; and PRT, $385 \mathrm{~L}$.

${ }^{b}$ Back-up message was generated. 
Detecting the diversions from the PCT and PRT proved to be more difficult. The 1and 2-L diversions were not detected at all. The 5- and 20-L diversions from the PRT were not identified with the normal diversion message but with a more ambiguous back-up message. This tends to happen when some of the expected discrepancies generate $z$ values above the threshold but others do not. The result is an incomplete discrepancy pattern and a less specific message.

The three vessels involved in the diversion experiments were equipped with essentially identical measurement instruments. This implies that the abrupt diversion detection sensitivity of MPM is not always limited by instrument accuracy. To understand the other factors that control MPM's sensitivity, the mode of operation of the three tanks must be considered in more detail.

The function of PST2 is to store concentrated uranyl nitrate solution until it is time to mix a new batch of feed solution in the PRT. Once the concentrated solution is transferred into PST2, a process that takes a few minutes, the tank level and density remain constant for the duration of the storage period. An abrupt diversion from PST2, or any other vessel, is detected by MPM when the level and volume measurements are substantially below their expected values. For these tests, the expected values were calculated by a straight-line extrapolation from previous measurements. If the measurements were perfect, such extrapolations would yield nearly perfect predictions since the level and density do not change appreciably in PST2 during the storage period. In reality, however, the imprecision, or repeatability, of a measurement will limit the effectiveness of the ex trapolation predictions. Despite the absence of serious uncertainties in the prediction model, MPM's diversion detection sensitivity would be limited by instrument imprecision. It is interesting that constant bias in a measurement would not bear directly on abrupt diversion detection sensitivity because all measurements would be affected about equally. Time-dependent errors such as instrument drift would have an adverse effect if the variation in the error is significant during the data acquisition interval, four minutes in this case.

In the cases of the PCT and PRT, measurement error was apparently not the factor that prevented the detection of small diversions. Both tanks were equipped with the same type of level and density measurement instruments used to detect the diversions from PST2. In both cases, however, the 5-L diversion was the smallest detected. The diminished sensitivity of MPM in these instances would appear to be the result of using inaccurate prediction models.

During normal operation, the PCT is continuously filled with concentrated uranyl nitrate from the concentrator (3PC in Fig. 2). As shown in Fig. 9, the rate of filling is not constant but oscillates over a fairly wide range. The oscillation is apparently caused by instabilities in the concentrator control system. Flow out of the concentrator is gravity motivated, and the output flow rate is thus primarily determined by a combination of the density and level of the solution in the concentrator. The pressure in the space above the solution might also have an effect on the output flow rate. The flow rate in to the concentrator is approximately constant. The solution density in the concentrator is controlled by automatically adjusting the rate of steam flow into the reboiler in response to solution density changes. The interaction of steam flow rate, solution density, solution level, overhead pressure, and output flow rate makes it difficult to model the concentrator's behavior with the simple equations currently used by MPM. 


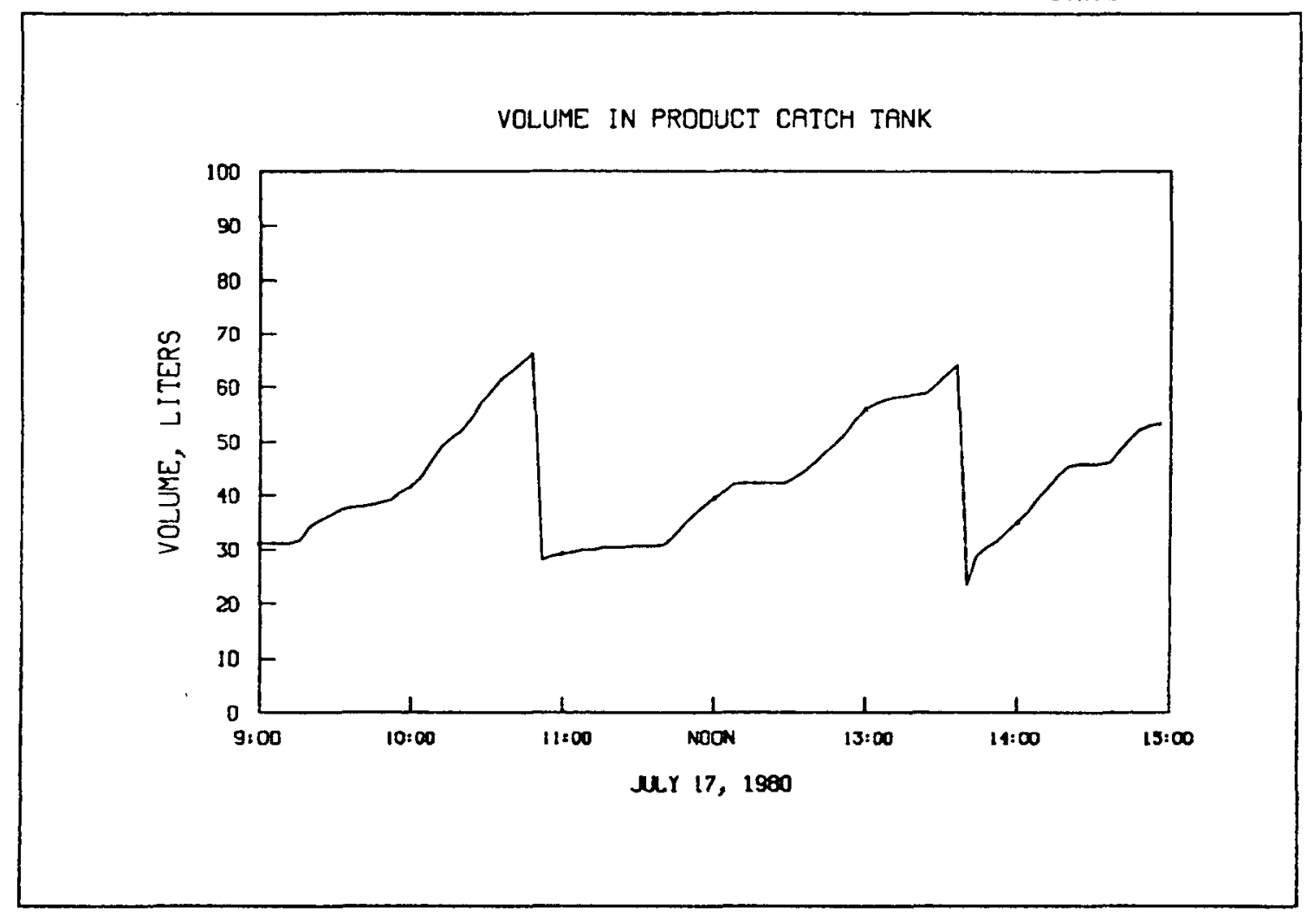

Fig. 9. Volume profile in the catch tank.

During the FY 1980 miniruns, straight-line extrapolations were used to model the filling profile of the PCT. Since the straight-line predictors were often inaccurate, the uncertainty factors used in calculating $z$ values for the PCT level and density had to be increased sufficiently to avoid frequent false alarms. The PCT level and volume uncertainties had to be increased until they were about five times the size of those used for PST2. This explains the degraded sensitivity of MPM in detecting diversions from the PCT.

The MPM system also failed to detect the 1- and 2-L diversions from the PRT, although not for exactly the same reason. The PRT is used to blend concentrated uranyl nitrate and fresh nitric acid. As batches of these two solutions are added to the tank, the measured density tends to fluctuate as shown in Fig. 10. With the instruments used in the miniruns, the measured density is actually the average density between the two deep probes (see Fig. 3). During the mixing period, the density between the probes is not constant. This causes an apparent fluctuation in level and volume. To avoid excessive false alarms during the mixing period, the PRT density, level, and volume uncertainties all had to be increased, thus reducing MPM's diversion detection sensitivity in this tank.

\subsubsection{Minirun four diversion tests}

The abrupt diversion tests conducted in minirun four (see Table 4) tended to confirm the results of the minirun three tests where detection sensitivity is concerned. Diversions 
ORNL-DWG. 81-17766
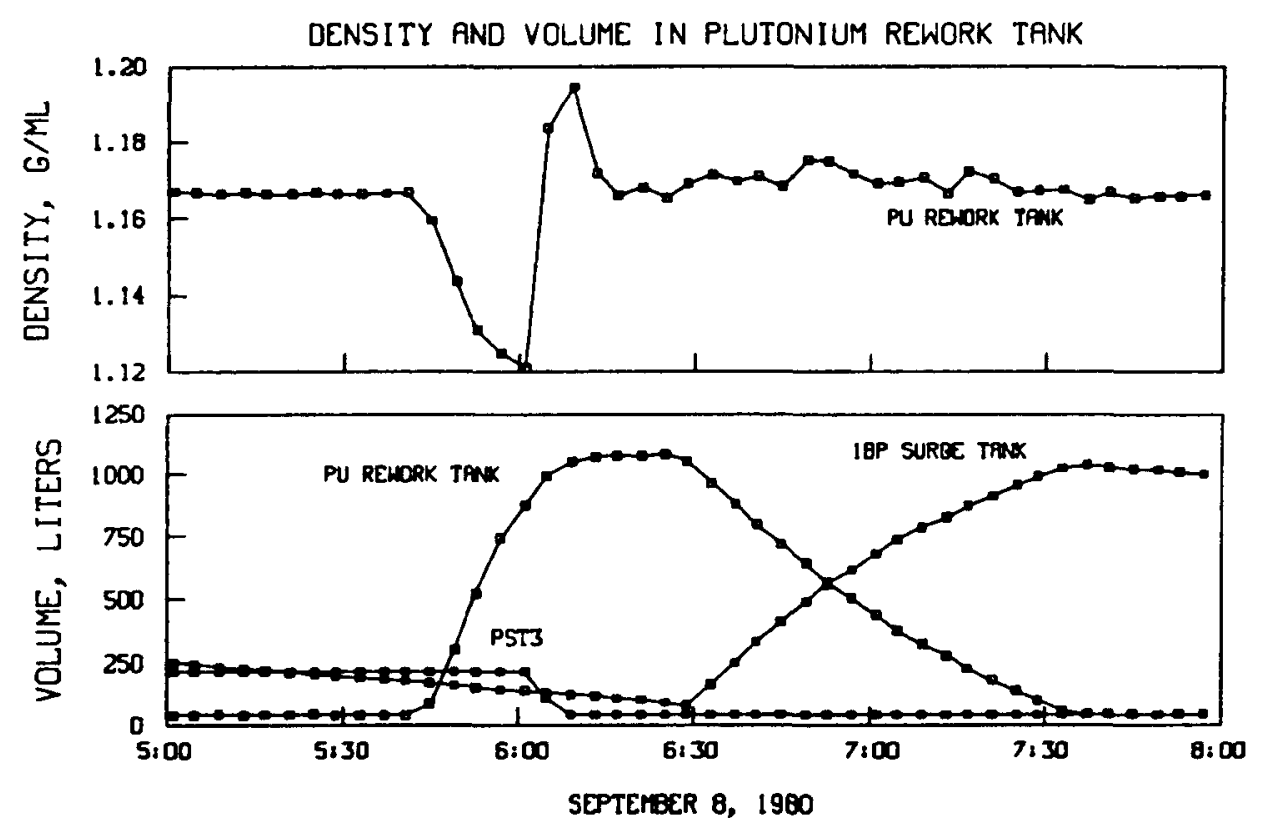

Fig. 10. Mixing in the rework tank.

Table 4. Abrupt diversion tests during minirun four

\begin{tabular}{lcc}
\hline \multicolumn{1}{c}{ Tank } & $\begin{array}{c}\text { Volume diverted } \\
(\mathrm{L})\end{array}$ & $z$ value \\
\hline Sample tank (PSAM) & 0.225 & \\
Storage tank 2 (PST2) & 2.0 & 13.0 \\
Storage tank 3 (PST3) & 1.75 & $3.7^{a}$ \\
Rework tank (PRT) & 2.0 & \\
1BP surge tank & 10.0 & $3.0^{a}$ \\
\hline
\end{tabular}

a"Unexpected Problem" messages were generated instead of the normal diversion message. 
from PST2 and PST3 in the 1- to 2-L range were detected. A small diversion from the sample tank (PSAM) was not detected, apparently because of the imprecision of the level and density measurement system. A 2-L diversion from the PRT was missed, and a 10-L diversion was barely indicated, as evidenced by the small $z$ value and the appearance of a secondary message. The secondary message appears when the level exceeds limits and the volume does not, or vice versa.

The most noticeable result of the minirun four diversion tests was the failure to detect a 20-L diversion from the 1BP surge tank. The 1BP surge tank is a large vessel that continuously feeds solution in to the $2 \mathrm{~A}$ column and is recharged at 8- to 12-h intervals with blended solution from the PRT. The temporal volume profile of the 1BP surge tank thus resembles a sawtooth curve, as shown in Fig. 11. (The spikes in Fig. 11 are caused by pressure probe blowouts, a phenomenon that will be discussed in Sect.4.3.) To maintain a steady flow rate into the $2 \mathrm{~A}$ column, the output stream from the surge tank is air-lifted to a constant level head-pot, as illustrated in Fig. 12. To ensure a constant head-pot level, the flow rate out of the surge tank is set higher than normally required, and the excess solution is allowed to overflow back into the top of the tank. This system creates a coupling between the level in the 1BP surge tank, the flow rate out of the tank, and the overflow rate back into the tank. This coupling is a possible cause of the oscillatory level changes superimposed on the sawtooth profile of the 1BP surge tank. Vortex effects in the head-pot are also a possible factor. In

ORNL-DWG. 81-17767

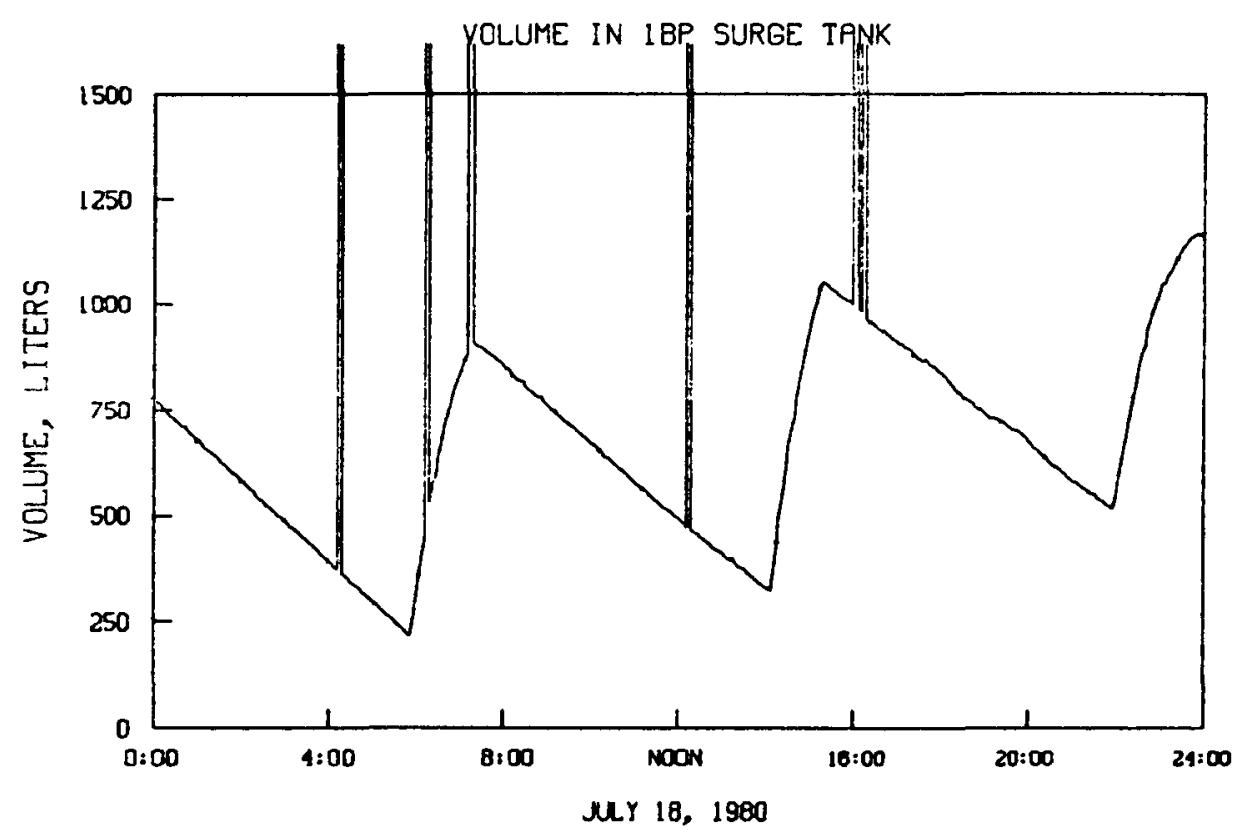

Fig. 11. Volume profile in the 1BP surge tank. 
ORNL DWG $81-1360$

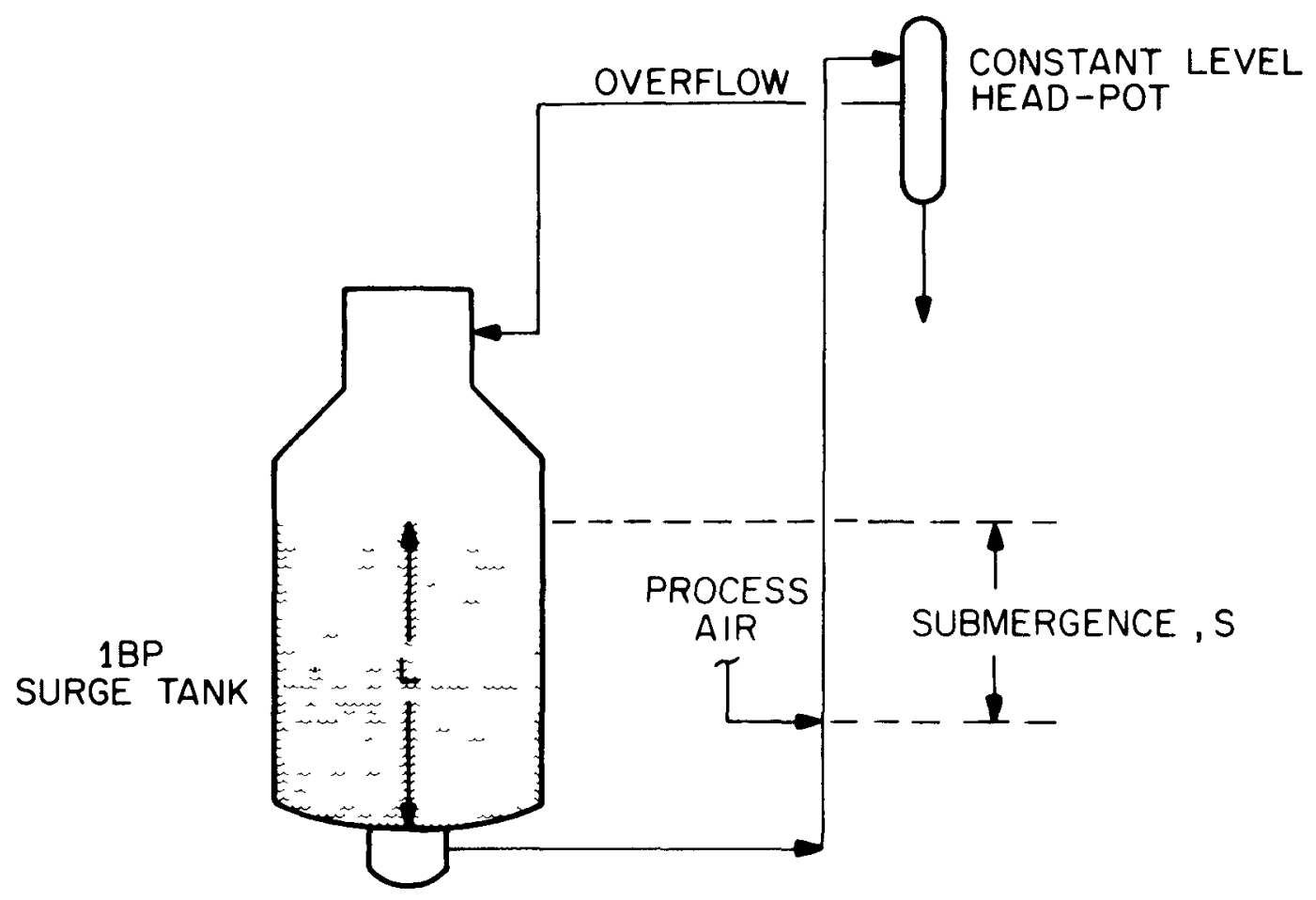

Fig. 12. Flow stabilization out of the 1BP surge tank.

any case, the level in the tank oscillates with an average period of a few minutes and an average amplitude of about 4 or $5 \mathrm{~L}$.

The level oscillations had a detrimental effect on MPM's diversion detection sensitivity for the same reasons discussed in connection with the catch tank. Excessive false alarm rates were avoided by increasing the uncertainties of the $1 \mathrm{BP}$ surge tank level and volume measurements.

In summary, the diversion tests indicated that MPM's abrupt diversion detection sensitivity can be limited by either of two factors: instrument error (especially imprecision) or inaccurate prediction models. Instrument error appeared to be the dominant limitation for the static storage tanks only. Improvements in measurement accuracy, although undoubtedly possible, lie beyond the scope of the MPM development project. Inaccurate prediction models were the limiting factors in detecting diversions from the 1BP surge tank, the catch tank, and the rework tank. In each of these cases, models could be modified to improve the MPM's sensitivity. At this time, modifications in the 1BP surge tank level and volume predictors are being evaluated. Unfortunately, nearly any model improvement will add complexity and bulk to the MPM code, and one of the goals of MPM has been the use of simple models. Trade-offs between model accuracy and complexity will be carefully considered during future phases of the MPM's development. 


\subsubsection{False alarms}

Currently, it is possible to provide only a rough summary of the incidence of false alarms during the MPM experiments. During the experiments themselves, more attention was paid to diversion detection sensitivity than to false alarms, and many of the false alarms could easily have been avoided by minor adjustments of the appropriate sensitivity factors. Retrospective assessment has, however, yielded some useful information about false alarm rates.

A false alarm is defined somewhat arbitrarily in the case of MPM. For the purpose of this report, a false alarm will be defined as the occurrence of a message indicating that the measured level in a tank is smaller than its predicted level, without the appearance of an overriding diagnostic message. That is, if the message indicating an abnormally low level is accompanied by a message indicating a batch transfer, probe blowout, or density anomaly, it does not qualify as a false alarm.

Table 5 summarizes the false alarms witnessed during miniruns three and four. The incidents have been partitioned into two categories, depending on the size of the apparent diversion. In general, the false alarms indicating small diversions could have been eliminated by increasing the appropriate uncertainty factors. The false alarms indicating large diversions, on the other hand, were apparently caused by measurement anomalies and would not have been eliminated by modest changes in the uncertainty factors. The occurrence of a few false alarms is, of course, expected. If no small false alarms are observed, one might assume that the pertinent uncertainty factors are too large, unnecessarily degrading MPM's diversion detection sensitivity.

The most noticeable feature of Table 5 is the large number of small false alarms in the PRT during minirun four. The level and volume uncertain ties used for the PRT were obviously too low. The reason for the instability of the PRT level is not entirely clear. Part of the

Table 5. False alarms during miniruns three and four ${ }^{a}$

\begin{tabular}{lccccc}
\hline & \multicolumn{4}{c}{ Number of false alarms } \\
\cline { 2 - 3 } Tank & \multicolumn{2}{c}{ Minirun 3 } & & \multicolumn{2}{c}{ Minirun 4 } \\
\cline { 2 - 3 } \cline { 2 - 5 } & Small $^{b}$ & Large & & Small & Large \\
\hline PCT & 1 & 2 & & 0 & 2 \\
PSAM & 7 & 1 & & 9 & 2 \\
PST1 & 4 & 0 & & 0 & 0 \\
PST2 & 0 & 0 & & 0 & 1 \\
PST3 & 0 & 1 & & 0 & 2 \\
PRT & 3 & 1 & & 23 & 4 \\
1BP & 0 & 0 & 0 & 0 \\
\hline
\end{tabular}

\footnotetext{
${ }^{a}$ For $14 \mathrm{~d}$ of operation.

${ }^{b}$ The cutoff between small and large is: PCT, 5 L; PSAM, PST1, PST2, and PST3, $2 \mathrm{~L}$; and PRT, $50 \mathrm{~L}$.
} 
problem may have been density fluctuations caused by the mixing of uranyl nitrate and nitric acid, as discussed earlier in this section. In many cases, however, substantial drops in the measured level were not accompanied by observable density variations. This situation merits further investigation.

The only other tank for which the uncertainty factors need to be increased is the sample tank (PSAM). For the second and third storage tanks (PST2 and PST3) and the 1BP surge tank, lowering the uncertainty factors to the point where an occasional false alarm occurs would probably be best.

\subsection{Batch Transfers}

Transfers of solution batches from one tank to another are among the most common process events. Reliable identification of batch transfers prevents confusing them with diversions and facilitates the detection of unauthorized process activities, an important consideration for international safeguards.

In the current MPM code, batch transfers are identified by recognizing patterns of $z$ values generated by the conservation equations. Each conservation describes a specific transfer. Its predictions are accurate when that transfer occurs or when no level changes in either of the subject tanks. Each equation will fail, however, when an adjacent transfer takes place, as illustrated in Fig. 13. When a transfer between tanks B and C occurs, Eqs. (1) and (3) will yield incorrect results and nonzero $z$ 's (see Fig. 13). Each transfer at the BNFP generated a unique pattern of nonzero $z$ 's.

During minirun four, 143 normal batch transfers occurred. In five instances, two transfers occurred simultaneously or overlapped to some extent. Fifteen transfers $(10.5 \%)$

ORNL DWG $81-1359$

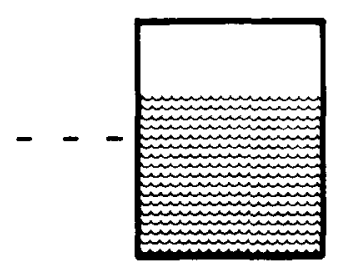

A

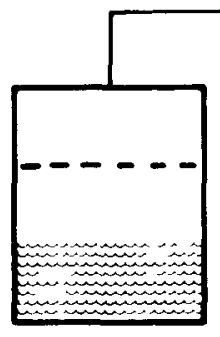

B

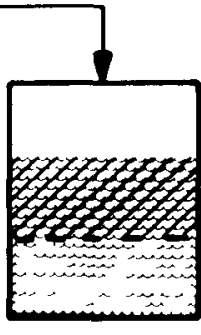

C

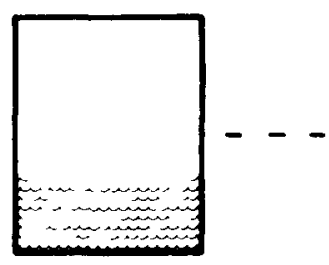

D
I. $\Delta V_{A}=-\Delta V_{B}$
INCORRECT
2. $\Delta V_{B}=-\Delta V_{C}$
CORRECT
3. $\Delta V_{C}=-\Delta V_{D}$
INCORRECT

Fig. 13. An example of the effect of a transfer on the MPM conservation equations. 
were not identified; eight of these were missed because of probe blowouts or density measurement anomalies. On one occasion, a single member of one of the paired transfers was missed. The other four multiple transfers were correctly identified. False transfer messages were generated 11 times, generally because of measurement anomalies. Many of the erroneous transfer messages involved the PRT.

The MPM's performance in batch transfer identification could be improved simply by adding information concerning valve positions and pump status. Binary signals from valves and pumps could easily be incorporated into the existing MPM code and used to confirm or deny the occurrence of a transfer. Provisions are being made to add valve position and pump status signals to the MPM data base at the BNFP.

\subsection{Probe Blowouts}

An operational problem frequently encountered during the miniruns was plugging of the pressure probes used to measure levels, densities, weights, and flow rates. The relatively dry air used to purge the pressure probes caused uranium salts to precipitate and adhere to the probe opening. If the salt buildup were not removed, it would eventually cause a substantial bias in the measured pressure difference. The BNFP staff has experienced this problem during previous cold operations. ${ }^{22}$ Salt accumulation can be minimized by humidifying the purge air; but, if the problem persists, the salt must be blown free by applying a short burst of high-pressure air to the probe. This is known as a probe blowout.

By using tabular data files for the fourth minirun, it was determined that individual probes were blown out 54 times. In every case, the MPM code correctly indentified the phenomenon as a blowout and identified the location. One false alarm occurred when an unusually abrupt transfer was momentarily identified as a blowout.

Blowouts are not difficult to identify. When high-pressure air is applied to a probe, the pressure reading increases by one or two orders of magnitude. This causes the MPM code to calculate an enormously high $z$ followed by an equally low $z$ at the next time period. Blowouts are distinguished from other phenomena by the magnitude of the $z$ values that they generate. 


\section{FUTURE WORK}

During the FY 1980 miniruns, MPM successfully identified the most common types of abrupt process events. It appears possible to extend MPM to permit the identification of slow phenomena and less common abrupt events. This section presents some priorities and possible approaches.

\subsection{Miscellaneous Measurement Anomalies}

Examination of data from the FY 1980 miniruns has indicated that anomalous measurements other than those caused by probe blowouts were frequent. These anomalies appear to fall into several indistinct categories. The only category that can currently be identified by MPM is the uncovering of a density or middle pressure probe (see Fig. 3). When the solution level drops below the density probe, the measured density abruptly drops to an abnormally low value (usually about $0.7 \mathrm{~g} / \mathrm{mL}$ ). This event is relatively easy to characterize and was reliably identified by MPM during minirun four.

In most other cases, the cause of the measurement anomalies has not been clearly identified. Some of the anomalies are repeatable enough that they could probably be recognized on an empirical basis. It is questionable, of course, how useful it would be to recognize that an event is occurring if one does not know its cause. Ultimately, three options are available: (1) attempt to determine the root cause of as many of the anomalies as possible and develop the prediction equations and matrices required to identify them, (2) develop the prediction equations and matrices to recognize repeated patterns even if the mechanisms behind them are unknown, or (3) abandon any effort to identify or even recognize these anomalies.

The best solution may be a combination of the options. Some of the anomalies are probably rare enough that it is not economical to try to identify them with MPM. Others seem to be fairly common and may be associated with routine transfer and mixing operations. It may be that empirical recognition of the anomalies (Option 2) could contribute heuristically to the fulfillment of Option 1.

\subsection{Slow-Event Monitoring}

The MPM code tested during the FY 1980 miniruns was designed to identify abrupt process events. The predictions used in the MPM analysis are based on data no more than 8 min old. Slow events, phenomena that do not cause noticeable changes in process variables over an 8-min period, cannot be directly detected with the existing system.

With respect to the BNFP plutonium cycles, three categories of slow events are of interest: slow diversions, slow instrument drift or other gradually changing measurement problems, and pulsed-column events. Detection of protracted diversions is viewed by many as one of the most critical objectives of advanced safeguards. Identification of instrument drift and related problems may be an important factor in the reliable detection of slow diversions. Certainly, the relationship between false alarms and unidentified measurement anomalies should be as close for protracted events as for abrupt ones. Diagnosis of changes in pulsed-column status would be useful for interpreting the results of material balances, avoiding false alarms, and detecting certain types of unauthorized process operation. Pulsed- 
column parameters, however, do not usually change rapidly enough to be assessed on the basis of an 8-min interval.

The general strategy for applying MPM to any of these problems would be to develop longer-term prediction models. No obvious reason prevents the MPM approach, using a large number of simple models and identifying process events by their patterns of successes and failures, from working for protracted events. On the other hand, when dealing with time periods of a few hours instead of a few minutes, it may be difficult to isolate relationships between process variables sufficiently to determine which patterns to associate with which events. This problem has not been studied in detail.

An important consideration is the extent to which other safeguards subsystems may be able to fulfill some of these functions. Dynamic accounting methods will possibly be effective in detecting protracted diversions if sufficiently accurate measurement techniques can be developed and implemented. Process monitoring strategies other than MPM may be better suited to the detection and identification of slow events in general. Conceivably, the monitoring of some slow phenomena, upon closer examination, may not prove to be particularly useful. A broad perspective is called for in evaluating the applicability of MPM to these problems. 


\section{CONCLUSIONS}

Four one-week experiments were conducted at the BNFP to test the practicability and sensitivity of microscopic process monitoring (MPM). The second and third plutonium cycles were operated with natural uranium feed solution, and data from 52 on-line process measurement instruments were analyzed and recorded.

The BNFP experiments clearly demonstrated that MPM can be implemented in a large reprocessing plant on a standard minicomputer system. No fundamental problems were encountered in accomplishing the rapid and frequent data acquisition required for MPM.

The experiments concentrated on the detection and identification of abrupt process phenomena, those that cause a measurable change in process parameters within $8 \mathrm{~min}$. The MPM technique proved successful in identifying abrupt diversion, batch transfers, and dip-tube blowouts. Data were compiled on the sensitivities and false alarm rates associated with these types of identification. 


\section{REFERENCES}

1. U.S. Nuclear Regulatory Commission, Office of Nuclear Material Safety and Safeguards, Safeguarding a Domestic Mixed Oxide Industry Against a Hypothetical Subnational Threat, NUREG-0414 (May 1978).

2. U.S. Nuclear Regulatory Commission, Office of Nuclear Material Safety and Safeguards, Report of the Material Control and Material Accounting Task Force, NUREG-0450 (April 1978).

3. M. Willich and T. B. Taylor, Nuclear Theft: Risks and Safeguards, Ballinger Publishing Co., Cambridge, Mass. (1974).

4. U.S. Congress, Office of Technology Assessment, Nuclear Proliferation and Safeguards, Praeger Publishers, New York (1977).

5. International Atomic Energy Agency, International Nuclear Fuel Cycle EvaluationINFCE Summary Volume, Vienna, Austria (1980).

6. International Atomic Energy Agency, Non-Proliferation and International Safeguards, Vienna, Austria (1978).

7. U.S. Nuclear Regulatory Commission, Office of Nuclear Material Safety and Safeguards, Potential Threat to Licensed Nuclear Activities from Insiders (Insider Study), NUREG-0703 (July 1980).

8. Nuclear Energy Policy Study Group, S. M. Keeny, Jr., Chairman, Nuclear Power Issues and Choices, sponsored by the Ford Foundation and administered by the MITRE Corporation, Ballinger Publishing Co., Cambridge, Mass. (1977).

9. M. Willich, International Safeguards and Nuclear Industry, Johns Hopkins University Press, Baltimore, Md. (1973).

10. J. T. Long, Engineering for Nuclear Fuel Reprocessing, American Nuclear Society, La Grange Park, Ill. (1978).

11. W. B. Bebbington, "The Reprocessing of Nuclear Fuels," Sci. Am. 235(6) (1976).

12. 10 CFR Pts. 0-99.

13. International Atomic Energy Agency, The Structure and Content of Agreements Between the Agency and States Required in Connection with the Treaty on the NonProliferation of Nuclear Weapons, INFCIRC/153, Vienna, Austria (June 1972).

14. T. Greenwood, H. A. Feiveson, and T. B. Taylor, Nuclear Proliferation, McGraw-Hill Book Co., New York (1977).

15. Atlantic Council of the United States, Nuclear Power and Nuclear Weapons Proliferation, Westview Press, Boulder, Colo. (1978).

16. E. A. Hakkila et al., Materials Management in an Internationally Safeguarded Fuels Reprocessing Plant, LA-8042 (three volumes) (April 1980).

17. R. Bodege et al., "Implications of Safeguarding Large Reprocessing Plants by Containment and Surveillance Methods," in Proceedings of the 2nd Annual Symposium on Safeguards and Nuclear Material Management, European Safeguards Research and Development Association, Edinburgh, Scotland (March 1980).

18. J. F. Ney, "Containment and Surveillance Systems for International Safeguards," in Inst. Nucl. Mater. Manage., Proc. Annu. Meet., 19th, Cincinnati, Ohio (June 1978).

19. P. W. Seabaugh et al., The Controllable Unit Approach to Material Control: Application to a High Throughput Mixed Oxide Process, NUREG/CR-1214 (MLM-2532, two volumes) (January 1980). 
20. R. H. Augustson, DYMAC Demonstration Program: Phase I Experience, LA-7126-MS (February 1978).

21. E. D. Blakeman et al., personal communication (December 1980).

22. J. M. Crawford et al., Nuclear Material Control and Accounting System Development FY 1979 Evaluation Report, AGNS-35900-2.2 (November 1979).

23. C. E. Johnson and A. P. Roe, "Material Control and Evaluation System at the ICPP," in Inst. Nucl. Mater. Manage., Proc. Annu. Meet., 20th, Piketon, Ohio (July 1979).

24. J. M. Crawford et al., Nuclear Material Control and Accounting System Evaluation Report - FY 1978 Integrated Uranium Run, AGNS-1040-2.2-50 (October 1978).

25. W. R. Hamel et al., personal communication (August 1978). 


$\begin{aligned} \text { 1. } & \text { R. L. Anderson } \\ \text { 2. } & \text { W. J. Armento } \\ \text { 3. } & \text { S. M. Babcock } \\ \text { 4. } & \text { J. E. Bigelow } \\ \text { 5. } & \text { R. D. Brooksbank } \\ \text { 6-8. } & \text { W. D. Burch } \\ \text { 9. } & \text { R. V. Clark } \\ \text { 10. } & \text { E. D. Collins } \\ \text { 11. } & \text { D. A. Costanzo } \\ \text { 12. } & \text { A. B. Crawford } \\ \text { 13. } & \text { M. J. Feldman } \\ \text { 14. } & \text { E. H. Gift } \\ \text { 15. } & \text { W. S. Groenier } \\ \text { 16. } & \text { T. L. Hebble } \\ \text { 17-21. } & \text { S. J. Hurrell } \\ 22 . & \text { R. T. Jubin } \\ 23 . & \text { M. V. Keigan } \\ 24 . & \text { H. T. Kerr } \\ \text { 25. } & \text { J. Q. Kirkman } \\ 26 . & \text { L. N. Klatt } \\ 27 . & \text { R. E. Leuze }\end{aligned}$

1. R. L. Anderson

2. W. J. Armento

3. S. M. Babcock

4. J. E. Bigelow

5. R. D. Brooksbank

9. R. V. Clark

anzo

12. A. B. Crawford

14. E. H. Gift

15. W. S. Groenier

21. S. J. Hurrell

22. R. T. Jubin

23. M. V. Keigan

24. H. T. Kerr

25. J. Q. Kirkman

27. R. E. Leuze
28. D. D. McCue

29. J. A. McEvers

30. J. M. McNair

31. G. W. Morrison

32. R. E. Norman

33. E. D. North

34. R. L. Philippone, DOE

35. R. T. Primm III

36. R. H. Rainey

37. H. H. Ross

38. W. F. Schaffer

39. J. H. Stewart, Jr.

40. W. E. Unger

41-42. J. W. Wachter

43. D. W. Williams

44. O. O. Yarbro

45. W. L. Zabriskie

46-47. Laboratory Records

48. Laboratory Records, ORNL-RC

49. ORNL Patent Office

\section{EXTERNAL DISTRIBUTION}

50-54. R. D. Hurt, 7915 Eastern Avenue, Silver Spring, Maryland 20910

55. Dr. R. Little, Princeton Plasma Physics Laboratory, James Forrestal Campus, P.O. Box 451, Princeton, New Jersey 08544

56-57. M. J. Lawrence, Director, Office of Nuclear Fuel Cycle, Department of Energy, Washington, D.C. 20545

58. Office of Assistant Manager for Energy Research and Development, DOE-ORO, Oak Ridge, Tennessee 37830

59-164. Given distribution as shown in TID 4500 under UC-86, Consolidated Fuel Reprocessing Category (25-NTIS) 